\title{
Nitrosative damage during retrovirus infection-induced neuropathic pain
}

\author{
Priyanka Chauhan, Wen S. Sheng, Shuxian Hu, Sujata Prasad and James R. Lokensgard
}

\begin{abstract}
Background: Peripheral neuropathy is currently the most common neurological complication in HIV-infected individuals, occurring in $35-50 \%$ of patients undergoing combination anti-retroviral therapy. Data have shown that distal symmetric polyneuropathy develops in mice by 6 weeks following infection with the LP-BM5 retrovirus mixture. Previous work from our laboratory has demonstrated that glial cells modulate antiviral T-cell effector responses through the programmed death (PD)-1: PD-L1 pathway, thereby limiting the deleterious consequences of unrestrained neuroinflammation.

Methods: Using the MouseMet electronic von Frey system, we assessed hind-paw mechanical hypersensitivity in LP-BM5-infected wild-type (WT) and PD-1 KO animals. Using multi-color flow cytometry, we quantitatively assessed cellular infiltration and microglial activation. Using real-time RT-PCR, we assessed viral load, expression of IFN- - , INOS, and MHC class II. Using western blotting, we measured protein nitrosylation within the lumbar spinal cord (LSC) and dorsal root ganglion (DRG). Histochemical staining was performed to analyze the presence of CD3, ionized calcium binding adaptor molecule (Iba)-1, MHCll, nitrotyrosine, isolectin B4 (IB4) binding, and neurofilament 200 (NF200). Statistical analyses were carried out using graphpad prism.

Results: Hind-paw mechanical hypersensitivity observed in LP-BM5-infected animals was associated with significantly increased lymphocyte infiltration into the spinal cord and DRG. We also observed elevated expression of IFN- $\gamma$ (in LSC and DRG) and MHC II (on resident microglia in LSC). We detected elevated levels of 3-nitrotyrosine within the LSC and DRG of LP-BM5-infected animals, an indicator of nitric oxide (NO)-induced protein damage. Moreover, we observed 3-nitrotyrosine in both small (IB4 $4^{+}$) and large (NF200 ${ }^{+}$) DRG sensory neurons. Additionally, infected PD-1 KO animals displayed significantly greater mechanical hypersensitivity than WT or uninfected mice at 4 weeks post-infection (p.i.). Accelerated onset of hind-paw hypersensitivity in PD-1 KO animals was associated with significantly increased infiltration of $\mathrm{CD}^{+}$and $\mathrm{CD}^{+} \mathrm{T}$ lymphocytes, macrophages, and microglial activation at early time points. Importantly, we also observed elevated levels of 3-nitrotyrosine and iNOS in infected PD-1 KO animals when compared with WT animals.

Conclusions: Results reported here connect peripheral immune cell infiltration and reactive gliosis with nitrosative damage. These data may help elucidate how retroviral infection-induced neuroinflammatory networks contribute to nerve damage and neuropathic pain.
\end{abstract}

Keywords: LP-BM5, MAIDS, Neuropathic pain, Reactive gliosis, Nitrosylation, PD-1 KO

\section{Background}

The life-saving effects of combination anti-retroviral (cART) therapy against HIV-1 have led to greater appreciation of the deleterious, long-term consequences of chronic viral infection-related complications; including neurological disorders, opportunistic infections, and tumors. One major consequence is peripheral neuropathic

\footnotetext{
*Correspondence: loken006@umn.edu

Department of Medicine, Neurovirology Laboratory, University of Minnesota Medical School, 3-107 Microbiology Research Facility, 689 23rd Ave. S.E, Minneapolis, MN 55455, USA
}

pain, which is currently the most common neurological complication in HIV-infected individuals occurring in an estimated $35-50 \%$ of patients undergoing cART [1-4]. Patients with distal symmetrical polyneuropathy (DSP), the most common peripheral neuropathy occurring with HIV infection, report debilitating effects on their quality of life such as painful, abnormal touch sensations (dysesthesias), burning, pins-and-needles sensations, and numbness which are often associated with mechanical allodynia [5]. These symptoms generally begin distally on the soles of the 
feet and are symmetrically distributed to legs, with upper extremities being affected later [6]. It is well-known that several ART drugs themselves can contribute to DSP [7-10]. But, in addition to neurotoxic drugs, antiviral responses and their associated inflammation are also known to induce neurotoxic mediators which have been linked to DSP [11]. Therefore, the urgent need to understand HIV-DSP pathogenesis, identify risk factors in addition to neurotoxic drugs, and develop effective preventative strategies will intensify as cART patients live longer.

Despite its clinical significance, neuropathic pain in the context of viral infection is still an under-studied area, in part because appropriate experimental animal models have not yet been developed. A number of murine, feline, and non-human primate models have been developed for investigation of HIV DSP [12-17]. However, most of these models are expensive and the wide array of powerful, transgenic, and knockout animals used to assess mechanisms in vivo are not available. In this study, we have employed the model of murine-acquired immunodeficiency syndrome (MAIDS), where mice are infected with the LP-BM5 retroviral mixture. LP-BM5 infection is a chronic persistent infection and mice develop an immunodeficiency syndrome, hence termed MAIDS. Mice never recover from infection and eventually succumb to infection by $10-14$ weeks. Most importantly, it has been reported that infected animals display symptoms of peripheral neuropathy by 6 weeks postinfection $[18,19]$. LP-BM5 rapidly infiltrates the CNS generating encephalitis, blood brain barrier dysfunction, and spacial memory deficits within 6-8 weeks postinfection $[18,20,21]$. The LP-BM5 retroviral mixture includes a non-pathogenic ecotropic (BM5eco) helper virus and the pathogenic yet replication-defective (BM5def) virus. While BM5def induces disease, it requires BM5eco to replicate [22]. While not a perfectly accurate representation of human AIDS, LP-BM5 replicates in murine cells, induces lymphopenia, immunodeficiency, and chronic immune dysregulation, including polyclonal B-cell activation, hypergammaglobulinemia, enhanced susceptibility to opportunistic pathogens, and the development of terminal B-cell lymphomas, all of which may contribute to DSP development [23]. Indeed, this infection model allows for the investigation of the immune mechanisms that drive chronic retroviral infection-induced neuropathic pain [24]. Finally, this natural retroviral infection model allows the application of powerful knockout and transgenic murine tools to investigate infection-induced DSP.

Our laboratory has been investigating the role of activated, brain-infiltrating peripheral immune cells in driving chronic activation of brain-resident microglia following viral infection, particularly through production of IFN- $\gamma$ [25-28]. Recent studies demonstrate that this type of chronic activation of resident glia is emerging as a common mechanism underlying various types of chronic pain $[29,30]$. Similar to the brain, it is likely that dysregulated peripheral immune activation also promotes analogous activation of resident glia within the spinal cord, as well as DRG, leading to nerve damage, neurotoxicity, and neuropathic pain [31]. Moreover, the presence of nitrotyrosine, a marker of peroxynitrite formation, in nerve biopsies from patients with inflammatory neuropathies has been demonstrated [32]. Despite increased understanding of the mechanisms that drive neuropathic pain; the interplay between the immune and nervous systems remains unclear.

In this study, we evaluated the extent of chronic immune activation within the LSC and DRG in MAIDS animals with peripheral neuropathy and its associated nitrosative damage. Further, we assessed the role of the PD-1: PD-L1 negative immune checkpoint pathway in development of chronic neuropathic pain. The inhibitory co-receptor PD-1 plays an important role in regulating functional exhaustion of virus-specific T-cells during chronic infections [33-36]. Functional impairment of $\mathrm{T}$-cells is characteristic of many chronic murine and human viral infections, including HIV/AIDS, due to the engagement of normal immune down-regulatory mechanisms, such as the PD-1/PD-L pathway [37]. A previous study from our laboratory has demonstrated the increased expression of PD-1 in MAIDS animals [26]. However, nothing is currently known regarding the development of neuropathic pain in PD-1 KO animals infected with LP-BM5. Here, we evaluated the development of neuropathic pain in PD-1 KO animals chronically infected with LP-BM5 and investigated its associated immune mechanisms and protein nitrosylation.

\section{Methods \\ Ethical approval}

This study was carried out in strict accordance with recommendations in the Guide for the Care and Use of Laboratory Animals of the National Institutes of Health. The protocol was approved by the Institutional Animal Care and Use Committee (protocol number: 1709-35110A and breeding protocol number: 1702-34587A) of the University of Minnesota. All animals were routinely cared for according to the guidelines of Research Animal Resources (RAR), University of Minnesota. Animals were sacrificed after isoflurane inhalation, whenever required and all efforts were made to ameliorate animal suffering.

\section{Virus and animals}

The LP-BM5 retrovirus mixture was obtained from the NIH AIDS reagent program (Germantown, MD, USA). LP-BM5 viral stocks were prepared as described previously [26]. Virus stocks used for infection were 
produced as cell-free supernatants of SC-1 cells. Titers were determined by a standard retroviral $\mathrm{XC}$ plaque assay for the BM5eco virus.

Pathogen free C57BL/6 (Jackson Laboratories, Wilmington, MA, USA) or PD-1 KO animals (kindly provided by Sing Sing Way, Cincinnati Children's Hospital) were housed in individually ventilated cages and were provided with food and water ad libitum at the RAR facility, University of Minnesota. Female mice were inoculated via the intraperitoneal (i.p.) route with two doses $\left(2 \times 10^{4} / \mathrm{PFU}\right.$ dose) of LP-BM5 retrovirus mixture in $500 \mu$, with 3 days between doses [26].

\section{Assessment of mechanical allodynia}

Tests of hind-paw mechanical hypersensitivity were conducted every week after 4 weeks of LP-BM5 infection until the designated end-point. Prior to testing, mice were allowed $20 \mathrm{~min}$ to habituate in the testing apparatus. Both left and right hind-paws were tested. Mechanical allodynia was assessed by using MouseMet electronic Von Frey system (Topcat Metrology, Cambridge, $\mathrm{UK})$. At least six bilateral measurements were taken for each animal. Data were calculated as the paw withdrawal threshold in grams of force. The behaviorist was blinded to the animal condition.

\section{Isolation of leukocytes from spinal cord and DRG for flow cytometry}

Mononuclear cells were isolated from the spinal cord of LP-BM5-infected wild-type (WT) and PD-1 KO mice using a previously described procedure with minor modifications [38-40]. In brief, whole tissues were harvested, ( $n=4-6$ animals/group/experiment), were minced finely using a scalpel in RPMI 1640 (2 g/L D-glucose and $10 \mathrm{mM}$ HEPES), and were digested in $0.0625 \%$ trypsin (in $\mathrm{Ca} / \mathrm{Mg}$-free HBSS) at room temperature for $20 \mathrm{~min}$. Single cell preparations of infected tissues were suspended in $30 \%$ Percoll and were banded on a 70\% Percoll cushion at $900 \times g$ for $10 \mathrm{~min}$ at $15{ }^{\circ} \mathrm{C}$. Total leukocytes obtained from the $30-70 \%$ Percoll interface were collected and counted on a hemocytometer using trypan blue dye exclusion method. To isolate mononuclear cells from DRG, we employed a non-enzymatic dissociation protocol described previously [41]. Briefly, six ganglia (L3-L5) were collected in a solution containing $1 \times \mathrm{HBSS} / 25 \mathrm{mM} \mathrm{HEPES} / 10 \%$ $\mathrm{FBS} / 10 \mu \mathrm{g} / \mathrm{ml}$ DNase ( $n=4-6$ animals/group/experiment). Animals were perfused with $1 \times$ HBSS and anesthetized using isoflurane before dissecting out the DRGs. Dissection was followed by homogenization of tissues with $1 \mathrm{ml}$ syringe attached with $21 \mathrm{G}$ needle and then $23 \mathrm{G}$ needle. The homogenized solution was filtered through a cell strainer, and the cells were counted as described previously.

Following preparation of single cell suspensions, cells were treated with Fc block (anti-CD32/CD16 in the form of 2.4G2 hybridoma culture supernatant with $2 \%$ normal rat and $2 \%$ normal mouse serum) to inhibit nonspecific $\mathrm{Ab}$ binding. Cells were then counted using the trypan blue dye exclusion method, and $1 \times 10^{6}$ cells were subsequently stained with anti-mouse immune cell surface markers for $15 \mathrm{~min}$ at $4{ }^{\circ} \mathrm{C}$ (anti-CD45-PE-Cy5 (eBioscience, San Diego CA, USA), anti-CD11b-AF700 (eBioscience), antiCD4-BV510 (BioLegend, San Diego CA, USA), anti-CD8PE-Cy7 (eBioscience), and anti-MHC-II-PE (eBioscience). Control isotype Abs were used for all fluorochrome combinations to assess nonspecific Ab binding. $10^{5}$ cells were acquired per sample by using a BD FACS LSR flowcytometer (BD Biosciences, San Jose CA, USA) by employing FACS DIVA software and were normalized to the total number of cells isolated from the spinal cord to calculate the number of CD4 T cells, CD8 T cells, and macrophages. Data were analyzed using FlowJo software (TreeStar, Ashland, OR, USA).

\section{Semi-quantitative real-time RT-PCR}

Total RNA from LSC (L3-L5) or DRG (L3-L5) tissue was extracted using an RNeasy Lipid Tissue Mini Kit (Qiagen, Valencia, CA, USA). The cDNA was synthesized from total RNA $(1 \mu \mathrm{g})$ using Superscript III reverse transcriptase (Invitrogen) and oligo $\mathrm{d}(\mathrm{T})_{12-18}$ primers (Sigma-Aldrich, St. Louis, MO, USA). PCR was performed with the SYBR Advantage qPCR master mix (ClonTech, Mountain View, CA, USA). The qPCR conditions were 1 denaturation cycle at $95{ }^{\circ} \mathrm{C}$ for $10 \mathrm{~s} ; 40$ amplification cycles of $95^{\circ} \mathrm{C}$ for $10 \mathrm{~s}, 60{ }^{\circ} \mathrm{C}$ annealing for $10 \mathrm{~s}$, and elongation at $72{ }^{\circ} \mathrm{C}$ for $10 \mathrm{~s}$ followed by 1 dissociation cycle (Stratagene, now Agilent Technologies, La Jolla, CA, USA). The relative expression levels were quantified using the $2^{-\Delta \Delta C t}$ method [42] and were normalized to the housekeeping gene hypoxanthine phosphoribosyl transferase (HPRT). The primer sequences were 5' - TGCTCGAGATGTCATGAAGG -3' sense, 5AATCCAGCAGGTCAGCAAAG-3' antisense for HPRT; 5' - ATGGCTGTTTCTGGCTGTTACTG-3' sense, 5' GACGCTTATGTTGTTGCTGATGG-3' antisense for IFN- $\gamma ; 5^{\prime}$ - CCAATGTGTCCATGTCATTT-3' sense, 5' CTTTCTCTCTCTGCTCATCGC -3' antisense for BM5eco; 5' - GAGTGGCCAAGTTTCGATGTGG-3' sense, 5' - CGGGGAAAAGGGAAGTGTCGAT-3' antisense for BM5def; 5'-GACGCTCAACTTGTCCCAAAAC-3' sense, 5' - GCAGCCGTGAACTTGTTGAAC-3' antisense for MHCII and 5' - TGGCCACCTTGTTCAGCTACG-3' sense, 5' - GCCAAGGCCAAACACAGCATA-3' antisense for iNOS.

\section{Immunohistochemistry (IHC)}

LSC (L3-L5) and DRG (L3-L5) tissues were harvested from both uninfected and LP-BM5-infected animals that were perfused with phosphate-buffered saline (PBS), $2 \%$ sodium nitrate, and 4\% paraformaldehyde. Tissues were 
subsequently submerged in $4 \%$ paraformaldehyde for $24 \mathrm{~h}$ (LSC) or $2 \mathrm{~h}$ (DRG) and were transferred to $25 \%$ sucrose solution for 2 days prior to sectioning. After blocking (10\% normal goat or donkey serum and $0.3 \%$ Triton X-100 in PBS) for $1 \mathrm{~h}$ at room temperature (RT), tissue sections were incubated overnight at $4{ }^{\circ} \mathrm{C}$ with either of the following antibodies: rat anti-mouse CD3 $(10 \mu \mathrm{g} / \mathrm{ml}$; R\&D Systems Inc., Minneapolis, MN, USA), rat anti-mouse MHCII (10 $\mu \mathrm{g} / \mathrm{ml}$; eBioscience), rabbit antibody to Iba-1 ( $2 \mu \mathrm{g} / \mathrm{mL}$; Wako Chemicals, Richmond, VA, USA), mouse antibody to nitrotyrosine $(5 \mu \mathrm{g} / \mathrm{ml}$; LifeSpan BioSciences,Inc., Seattle, WA, USA), mouse antibody to neuron specific class III ßeta-tubulin $(10 \mu \mathrm{g} / \mathrm{ml}$; R\&D Systems Inc.), and rabbit antibody to neurofilament 200 (NF200, 1:80, Sigma-Aldrich, Australia). For fluorescent detection, sections were incubated with Cy3-conjugated donkey anti-goat or donkey anti-rabbit Ab (Jackson Immunoresearch Labs), Alexa Fluor 488 conjugated donkey anti-mouse and/or Alexa Flour 546 conjugated donkey anti-rat antibodies (Molecular Probes).

For nitrotyrosine staining, tissue sections were pretreated using heat-induced epitope retrieval. After washing three times with TRIS-buffered saline (TBS), secondary Ab (goat anti-mouse IgG biotinylated; Vector Labs, Burlingame, CA, USA) was added for $1 \mathrm{~h}$ at RT followed by incubation with $A B C$ (avidin-biotinylated enzyme complex, Vector Labs) solution. For isotype staining, mouse IgG was used as primary antibody. The peroxidase detection reaction was carried out using 3,3'-diaminobenziding tetrahydrochloride (DAB; Vector Labs) for several minutes at RT. For nitrotyrosine and NF 200 double immunolabeling, tissue sections were incubated with both the primary antibodies simultaneously, overnight at $4{ }^{\circ} \mathrm{C}$. After washing four times in PBS-T (PBS with $0.5 \%$ Triton X-100), sections were incubated for $1 \mathrm{~h}$ with Alexa Fluor 488 and/or Alexa Fluor 546 secondary antibodies (1:500, Molecular Probes). For nitrotyrosine and IB4 double staining, sections were stained with nitrotyrosine as described previously. After incubation with Alexa Fluor 546 goat anti-mouse secondary antibody (1:500, Molecular Probes), sections were washed twice with PBS-T and twice with PBS followed by a $2 \mathrm{~h}$ incubation with FITC-conjugated IB4 (1:100, Sigma Aldrich, Australia). After immunostaining, sections were washed in PBS-T four times and were counterstained with $1 \mu \mathrm{g} / \mathrm{ml}$ 4,6-diamidino-2-phenylindole (DAPI, Sigma Aldrich). Fluorescence was detected using appropriate filter combinations for DAPI, FITC/Alexa Fluor 488, Alexa Fluor 546/Cy3.

To evaluate the percentage of nitrotyrosine- and IB4or NF200- double-positive sensory neurons, serial sections of DRGs (L3-L5) from three to four animals were cut $(7 \mu \mathrm{m})$ and stained. At least four sections per DRG per animal were imaged and counted at $\times 20$ magnification. The percentage of double-labeled neurons was calculated by dividing the total number of double-labeled neurons by the number of single IB4- or NF200-labeled neurons $\times 100$.

\section{Western blotting}

Animal tissues were harvested in T-PER (Thermo Scientific, Rockford, IL, USA) containing protease inhibitor (SigmaAldrich), were homogenized with a polytron on ice, and were centrifuged at $12,000 \times g$ for $20 \mathrm{~min}$ at $4{ }^{\circ} \mathrm{C}$. Supernatants were collected and protein concentrations were measured with the Bio-Rad Protein Assay reagent (Bio-Rad Laboratories, CA, USA). Protein samples $(45 \mu \mathrm{g})$ were mixed with $2 \times$ sample buffer (Bio-Rad Laboratories), were heated at $100{ }^{\circ} \mathrm{C}$ for $5 \mathrm{~min}$ and then were electrophoresed onto 4-20\% pre-cast gels (Bio-Rad Laboratories) followed by transblotting to nitrocellulose membranes $(0.45 \mu \mathrm{m})$. Membranes were rinsed in TTBS (Tris- $\mathrm{HCl}$ with $\mathrm{NaCl}$ and Tween 20) and were incubated in 5\% blocking buffer (blotto in TTBS, Santa Cruz) for $1 \mathrm{~h}$ at room temperature before being probed with primary antibody (mouse anti-nitrotyrosine, MAB5404, 1:1000 in 1\% blotto; Chemicon, now Millipore) overnight at $4{ }^{\circ} \mathrm{C}$. After washing $3 \times$ with TTBS, membranes were incubated in alkaline phosphatase (AP) conjugated-secondary antibody (1:5000 in $1 \%$ blotto, Promega) at room temperature for $1 \mathrm{~h}$. Membrane blots were washed $3 \times$ with TTBS followed by $2 \times$ assay buffer $(1 \times)$ and then were incubated in substrate solution (CDP-Star, Applied Biosystems, now Thermal Fisher) for $10 \mathrm{~min}$. The signal intensity of the protein bands was measured by employing Image Studio Lite software (LI-COR, Lincoln, NE, USA).

\section{Statistical analysis}

One-way analysis of variance (ANOVA) with Tukey's multiple comparison test was employed for graphical analysis. One-way ANOVA post hoc followed by Fisher's PLSD test was used for the analysis of behavioral testing. Differences were considered significant, when $p<0.05$. For statistical analysis and generation of graphs, Prism 5 software (Version 5.01; GraphPad Software Inc., CA, USA) was used.

\section{Results}

Establishment of LP-BM5 infection-induced neuropathic pain and its associated chronic immune activation

Mice infected with the LP-BM5 retrovirus mixture have previously been reported to display symptoms of DSP by 6 weeks p.i. by Cao et al. [18]. We were able to repeat these findings using the MouseMet electronic von Frey system. LP-BM5-infected C57BL/6 mice exhibited hindpaw mechanical hypersensitivity after 5 weeks of infection, with no significant differences between the left and right hind-paws (Fig. 1a). Animals exhibited pain until 10 weeks post-infection when the majority of analyses 

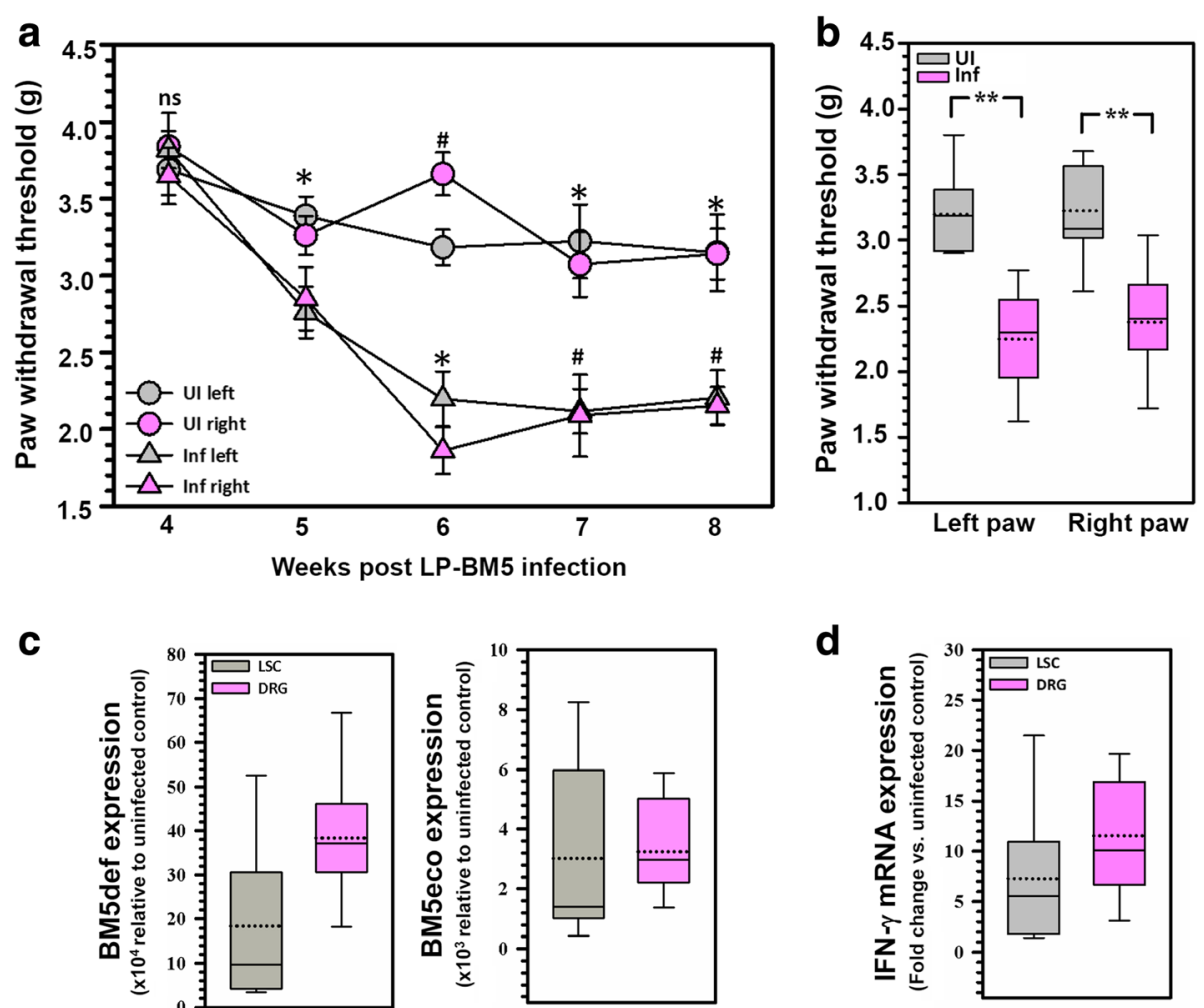

Fig. 1 Establishment of LP-BM5 infection-induced neuropathic pain and associated chronic immune activation. a WT animals were randomly assigned to LP-BM5-infected (Inf) and uninfected (UI) groups ( $n=10 /$ group). Hind-paw withdrawal threshold (in grams) was assessed on both left and right paws at various time points via MouseMet electronic Von Frey. ${ }^{*} p<0.05$ between infected (Inf) and uninfected (UI) WT animals, and $\# p<0.05$ between infected (Inf) and uninfected (UI) WT animals (left and right paws, respectively). Data are presented as mean \pm SEM paw withdrawal threshold. $\mathbf{b}$ Hind-paw withdrawal threshold (in grams) was assessed on both left and right paws at 10 weeks p.i. via MouseMet electronic Von Frey ( $n=10 /$ group). ${ }^{* *} p<0.01$ between infected (Inf) and uninfected (UI) WT animals. Data are presented as mean \pm SEM paw withdrawal threshold. c LP-BM5 viral loads were determined by measuring the levels of BM5def (disease-inducing virus) and BM5eco (helper virus) gag RNA in the LSC (L3 to L5) and DRG ( $n=12)$ during MAIDS at 10 weeks p.i. via real-time RT-PCR. Results are presented as box plots of pooled data from individual animals. d Chronic IFN- $\gamma$ mRNA production was measured in LSC (L3 to L5) and DRG $(n=12)$ at 10 weeks p.i. via real-time RT-PCR. Results are presented as box plots of pooled data from individual animals

were carried out (Fig. 1b). In addition, we also examined LP-BM5 retroviral load by measuring levels of BM5def (disease-inducing virus) and BM5eco (helper virus) gag RNA via real-time RT-PCR in the LSC and DRG of infected MAIDS animals and found high viral loads persisting within both tissues at 10 weeks p.i. (Fig. 1c). We also observed elevated mRNA levels of IFN- $\gamma$, 7-fold in LSC and 12-fold in DRG (Fig. 1d).

\section{Increased $\mathrm{CD}^{+}$and $\mathrm{CD}^{+}{ }^{+}$-cell infiltration into the spinal cord and DRG of MAIDS mice with DSP}

We next examined the infiltration of $\mathrm{CD}^{+}$and $\mathrm{CD} 8^{+} \mathrm{T}$ lymphocytes into the spinal cord of animals with DSP at 10 weeks p.i. Representative flow cytometry plots (Fig. 2a) show that LP-BM5 infection resulted in an increased frequency of both $\mathrm{CD} 4^{+}$and $\mathrm{CD} 8^{+} \mathrm{T}$-cells within the spinal cord. As shown in Fig. 2b, c, mice infected with LP-BM5 exhibited significant increase in the absolute numbers of $\mathrm{CD}^{+}$and $\mathrm{CD}^{+} \mathrm{T}$-cells in spinal cord when compared to uninfected mice. Furthermore, IHC staining of LSC sections from infected animals confirmed the presence of infiltrating $\mathrm{CD}^{+} \mathrm{T}$ cells (white arrows) in the meningeal area, dorsal, and ventral horn of spinal cord (Fig. 2d). We did not observe any significant difference in the total number of myeloid cells in uninfected and LP-BM5-infected animals. In addition to spinal cord, we also carried out flow cytometric analyses of DRG tissues to assess infiltration of $\mathrm{CD}_{4}^{+}$and $\mathrm{CD}^{+}{ }^{+} \mathrm{T}$ lymphocytes. In these studies, we observed a significant increase in the number of $\mathrm{CD} 4^{+}$ T-cells infiltrating the DRG (Fig. 3a, b). However, we did not observe increased, infection-induced $\mathrm{CD} 8^{+} \mathrm{T}$-cell infiltration (Fig. 3a, c).

\section{Activation of resident microglial cells in the spinal cords of MAIDS mice with DSP}

We next assessed activation of resident microglial cells in the LSC by determining levels of markers for reactive 

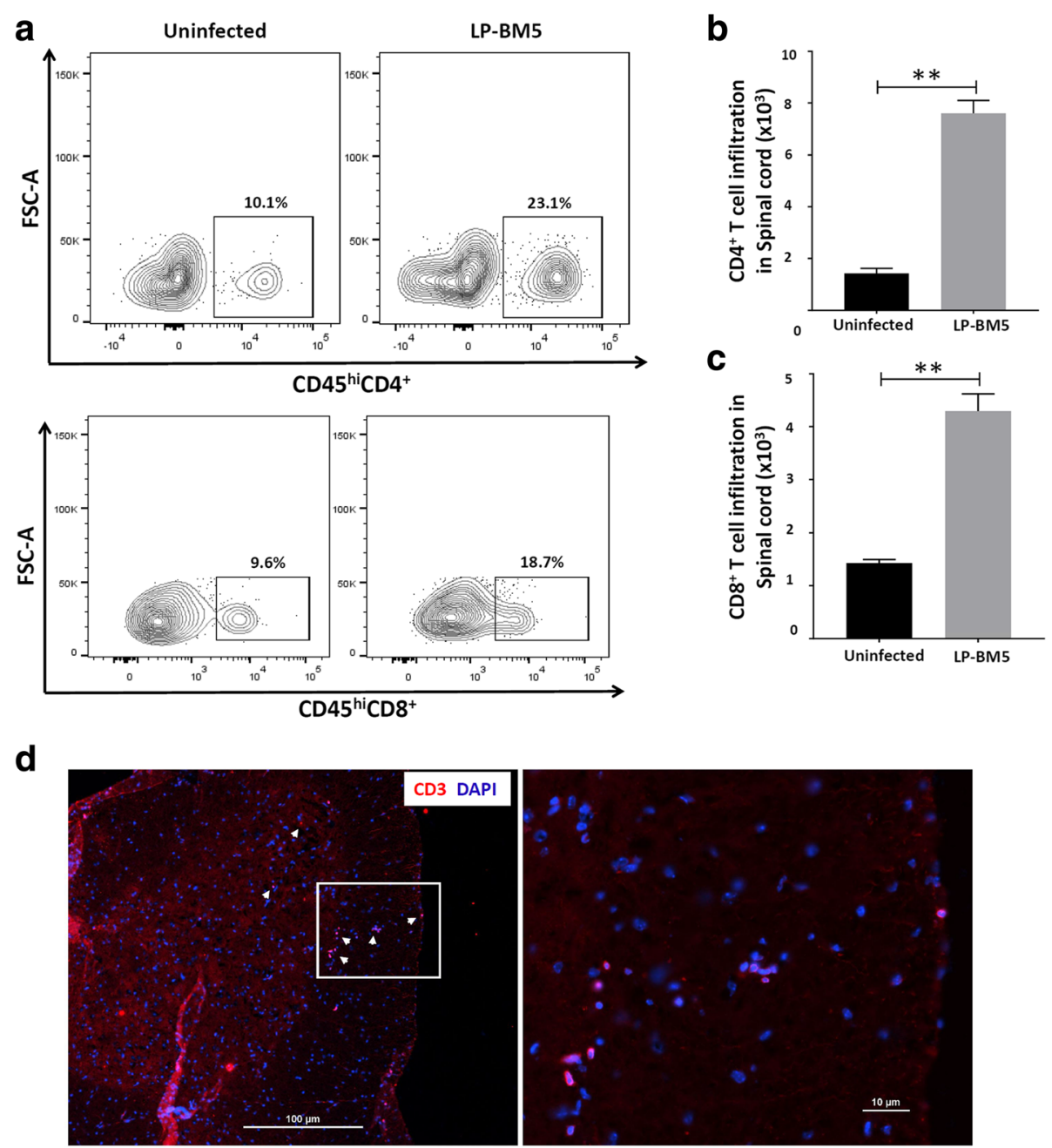

Fig. 2 Increased infiltration of $C D 4^{+}$and $C D 8^{+}$T-cells into the spinal cord of LP-BM5-infected animals. Spinal cord-infiltrating leukocytes were banded on a 30-70\% Percoll cushion, collected, and labeled with Abs specific for anti-CD45-PE-Cy5, anti-CD11b-AF700, anti-CD4-BV510, and anti-CD8-PE-Cy7 for analysis by flow cytometry. a Representative contour plots show the percentages of $\mathrm{CD} 4^{+}$and $\mathrm{CD} 8^{+} \mathrm{T}$ lymphocytes within uninfected and infected (LP-BM5) spinal cords of WT at 10 weeks p.i. b CD4 ${ }^{+}$T-cell infiltration into the spinal cord of uninfected and LP-BM5-infected animals. c CD8 ${ }^{+}$T-cell infiltration into the spinal cord of uninfected and infected animals. Pooled data present absolute numbers (mean $\pm \mathrm{SD}$ ) of $\mathrm{CD} 4^{+}$and $\mathrm{CD} 8^{+} \mathrm{T}$-cells from two independent experiments using 4-6 animals per group. ${ }^{* *} p<0.01$. $\mathbf{d} \| \mathrm{HC}$ staining of infiltrating CD3+ T-cells in LSC (L3 to L5) sections from infected animals. White arrows indicate $\mathrm{CD}^{+} \mathrm{T}$ cells (red). Scale bar $=100 \mu \mathrm{m}$. The right panel indicates the $\times 40$ image of the rectangular area. Scale bar $=10 \mu \mathrm{m}$

gliosis [25, 28, 43]. Firstly, we have used Iba I for IHC staining of infected LSC and DRG tissues, a marker that will stain both the microglia and infiltrating macrophages. IHC staining (red) confirmed the presence of both microglia and macrophages within infected LSC and DRG at 10 weeks p.i. Staining for neuron-specific class III $\beta$-tubulin was also performed (green), (Fig. 4a). This was followed by quantification of the $\mathrm{CD} 45^{\text {int }} \mathrm{CD} 11 \mathrm{~b}^{\text {hi }}$ population of microglial cells and their expression of MHCII in the spinal cord of MAIDS mice using flow cytometry. We observed $38.8 \pm 2.8 \%$ of microglial cells expressing MHCII with LP-BM5-infected mice as compared to $1.5 \pm 0.6 \%$ microglial cells of uninfected mice (Fig. $4 \mathrm{~b}$ ). These data were substantiated using real-time RT-PCR for
MHCII mRNA expression (Fig. 4c) and IHC staining for MHCII (brown) (Fig. 4d), both indicating the upregulation of MHCII in the LSC of mice infected with LP-BM5 at 10 weeks p.i. We did not observe a $C D 45^{\text {int }} \mathrm{CD} 11 b^{\text {hi }}$ population in DRG.

\section{Nitric oxide (NO)-mediated protein damage within the LSC and DRG of LP-BM5-infected animals}

Since neuropathic pain is a response to damage, we probed proteins in both LSC and DRG tissues from infected, as well as uninfected, animals for NO-mediated protein damage (i.e., protein nitrosylation) at 10 weeks post-LP-BM5 infection. We analyzed expression of 3nitrotyrosine in MAIDS animals with DSP by both 

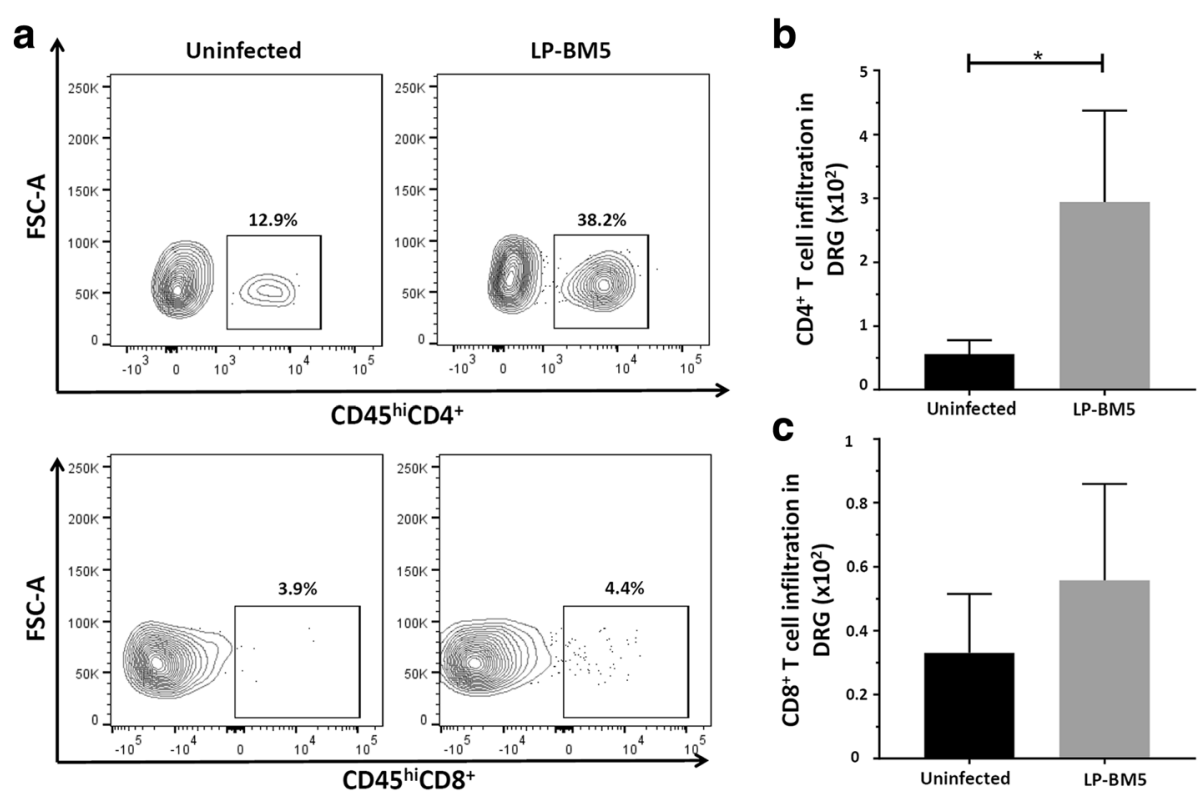

Fig. 3 Increased infiltration of CD4 ${ }^{+}$T-cells into the DRG of LP-BM5-infected animals. Mononuclear cells from six ganglia (L3-L5) were isolated using a non-enzymatic dissociation method and were labeled with Abs specific for anti-CD45-PE-Cy5, anti-CD4-BV510, and anti-CD8-PE-Cy7 for analysis by flow cytometry. a Representative contour plots show the percentages of $C D 4^{+}$and $C D 8^{+} T$ lymphocytes within uninfected and infected (LP-BM5) DRG of WT animals at 10 weeks p.i. $\mathbf{b}$ CD4 ${ }^{+}$T-cell infiltration into the DRG of uninfected and LP-BM5-infected animals. c CD8 ${ }^{+}$T-cell infiltration into the DRG of uninfected and infected animals. Pooled data present absolute numbers (mean $\pm \mathrm{SD}$ ) of $\mathrm{CD} 4^{+}$and $\mathrm{CD} 8^{+} \mathrm{T}$-cells from two independent experiments using 4-6 animals per group. ${ }^{*} p<0.05$

immunoblotting and IHC staining. We observed significantly greater infection-induced protein nitrosylation in the LSC (Fig. 5a), as well as DRG (Fig. 5b) from infected animals as compared to their uninfected littermates by immunoblotting. Interestingly, in both LSC and DRG, two major protein bands were nitrosylated following LPBM5 infection. We quantified the signal intensity of both these bands (indicated $\mathrm{a}$ and $\mathrm{b}$ in Fig. 5a, b). Furthermore, LSC and DRG tissues from infected animals with MAIDS were cryosectioned and were stained with anti-nitrotyrosine Abs in situ (Fig. 5c). Positive staining cells (brown) were observed in LPBM5-infected, but not uninfected sections of both LSC and DRG. Further characterization of the damaged neurons showed that 3-nitrotyrosine was co-localized in both $\mathrm{IB}_{4}^{+}$, small and $\mathrm{NF}^{-} \mathrm{OO}^{+}$, large sensory neurons in the DRG of infected animals (Fig. 6a, b, respectively). We observed a significant increase in the percentage of $\mathrm{IB}^{+}{ }^{+}$or $\mathrm{NF}_{200^{+}}$sensory neurons that were co-labeled with nitrotyrosine in LP-BM5-infected animals as compared to uninfected animals (Fig. 6c, d, respectively).

Accelerated onset of hind-paw mechanical hypersensitivity in PD-1 KO animals infected with LP-BM5 and associated immune dysregulation

To determine if LP-BM5 would induce signs of peripheral neuropathy in chronically infected PD-1 KO animals, we examined hind-paw mechanical hypersensitivity as described in the previous section. No significant differences were found between the left and right hind-paws of infected or uninfected PD-1 KO animals. When infected PD-1 KO animals were monitored for mechanical allodynia, we observed a significant drop in paw withdrawal threshold at 4 weeks post-LP-BM5 infection and thereafter when compared with uninfected animals (Fig. 7a). Moreover, when compared with infected WT animals which developed mechanical allodynia at 5 weeks, PD-1 KO animals developed earlier mechanical allodynia by 4 weeks (Fig. 7b). No significant hind limb paralysis or weakness was observed in any of the infected mice. However, there was apparent splenomegaly and enlargement of lymph nodes in LP-BM5-infected animals.

We next examined the number of $\mathrm{T}$ lymphocytes infiltrating the spinal cord of WT and PD-1 KO mice to determine if it was associated with the earlier onset of mechanical hypersensitivity observed in PD-1 KO animals. Hence, we evaluated immune cell infiltrates in the spinal cord at 4 weeks p.i. The representative flow cytometry plots in Fig. 7c show that LP-BM5 infection resulted in an increased frequency of both $\mathrm{CD}_{4}^{+}$and $\mathrm{CD}^{+}$T-cells within the spinal cord of PD-1 KO animals as compared with WT mice. As shown in Fig. 7d, e, PD-1 KO mice infected with LP-BM5 exhibited a significant increase in the absolute numbers of $\mathrm{CD} 4^{+}$ and $\mathrm{CD}^{+}$T-cells in spinal cord when compared to infected WT mice. 


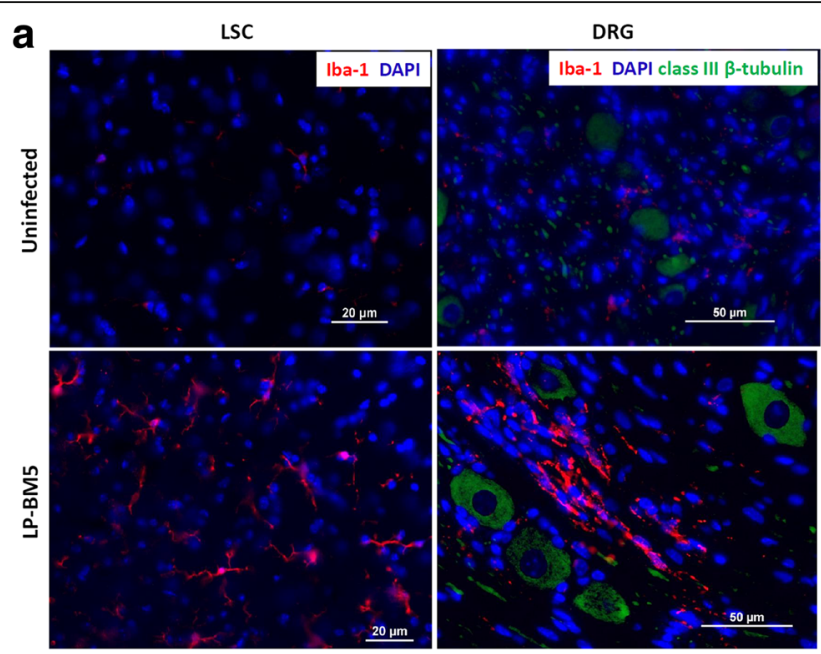

\section{C}

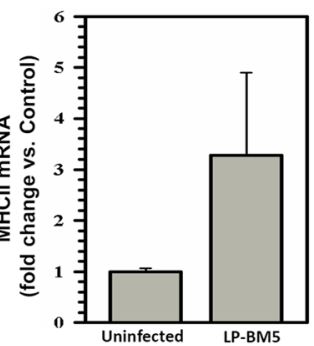

b

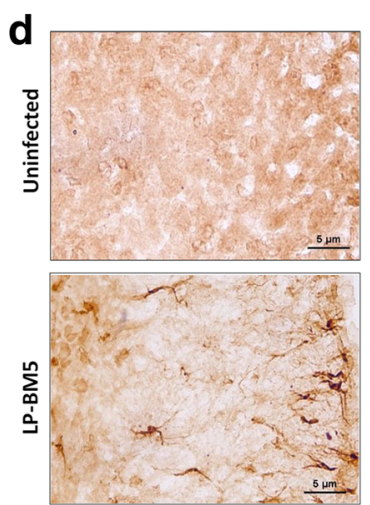

Fig. 4 Chronic activation of resident microglial cells in LP-BM5-infected animals. a IHC staining of the macrophage/microglial cell marker, Iba-1 (red) within infected LSC (L3-L5), and DRG at 10 weeks p.i. Green staining is for neuron-specific class III $\beta$-tubulin. Blue is DAPI staining. Scale bar $=20 \mu m$ for LSC and $50 \mu \mathrm{m}$ for DRG. $\mathbf{b}$ Resident microglial cells in the spinal cord of uninfected and infected animals were analyzed for expression of the activation marker MHCII. Contour plots showing the frequency of microglial cells expressing MHCII within uninfected and infected (LP-BM5) spinal cords of animals at 10 weeks p.i. Pooled data present the frequency (mean \pm SD) of microglial cells expressing MHCII in spinal cord of uninfected and infected animals at 10 weeks p.i. from two independent experiments using 4-6 animals per group. Inset, isotype control. c MHCll expression was measured by real-time RTPCR in the LSC of uninfected and infected (LP-BM5) animals $(n=4-6)$ at 10 weeks p.i. $\mathbf{d} \| \mathrm{HC}$ staining of MHCII (brown) in LSC sections from uninfected and infected (LP-BM5) animals. Scale bar $=5 \mu \mathrm{m}$

Leukocytes isolated from the spinal cord were subsequently stained with flourochrome-tagged monoclonal antibodies against CD45 and CD11b. Flow cytometric analysis of CD45- versus CD11b-expression can be used to differentiate tissue-infiltrating macrophages from resident microglial cells [28, 43, 44]. Gating on the $\mathrm{CD} 45^{\mathrm{int}} \mathrm{CD} 11 \mathrm{~b}^{\mathrm{hi}}$ population identified the microglial cell population, while $\mathrm{CD} 45^{\mathrm{hi}} \mathrm{CD} 11 \mathrm{~b}{ }^{\mathrm{hi}}$ cells were identified as infiltrating macrophages (Fig. 8a). The total number of macrophages was enumerated. A significant increase in the absolute number of macrophages infiltrating the spinal cord following LP-BM5 infection in PD-1 KO animals, when compared with WT mice, was observed at 4 weeks p.i. (Fig. 8b). We next assessed activation of resident microglial cells by determining expression levels of MHC class II. We observed a significant upregulation of MHCII expression on microglia $(34.0 \pm 5.4 \%)$ in the spinal cord of LP-BM5-infected PD-1 KO animals as compared with infected WT animals (7.9 $\pm 1.2 \%)$, (Fig. 8c).

\section{Increased NO-mediated protein damage within the LSC and DRG of LP-BM5-infected PD-1 KO animals}

We next assessed infection-induced NO-mediated protein damage in PD-1 KO animals as compared with WT animals using immunoblotting as described in the previous section. As shown in Fig. 9a, b, we observed nitrosylation of proteins in both WT and PD-1 KO animals infected with LP-BM5 as compared to their agematched, uninfected littermates in both LSC and DRG. Significantly higher levels of 3-nitrotyrosine were observed in LP-BM5-infected PD-1 KO animals as compared with infected WT animals in LSC (Fig. 9a). However, in the DRG, we observed comparable levels of protein nitrosylation between LP-BM5-infected PD-1 
a

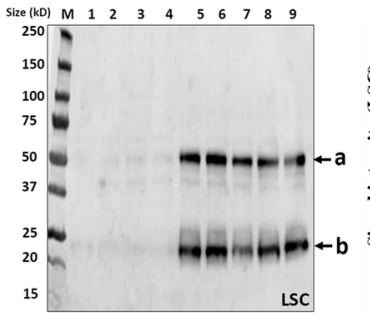

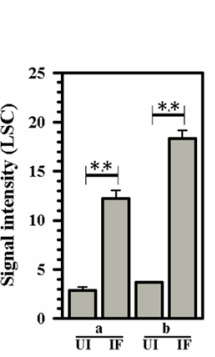

b

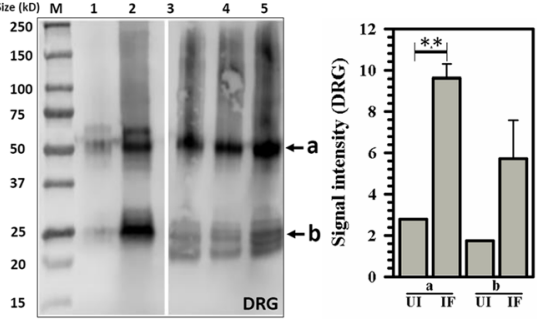

C

Uninfected

LP-BM5

Isotype
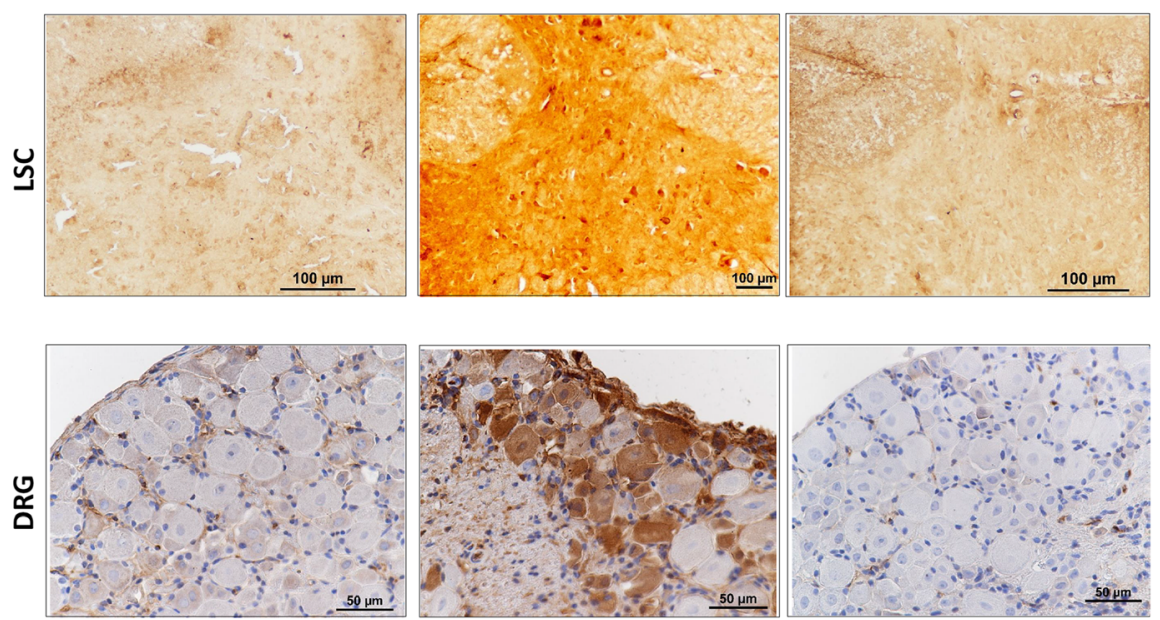

Fig. 5 NO-induced damage within the LSC and DRG of LP-BM5-infected animals. a Western blot of LSC tissue lysates from uninfected (UI, lanes 1 to 4) and LP-BM5-infected (Inf, lanes 5 to 9) animals probed with anti-3-nitrotyrosine antibodies. Each lane displays tissue extract from one animal at 10 weeks p.i. The band labeled $\mathbf{a}$ identifies a high molecular weight (MW) protein band, while the $\mathbf{b}$ band points out a lower MW protein, both of which are nitrosylated. The signal intensity of both the $\mathbf{a}$ and $\mathbf{b}$ protein bands for uninfected (UI) and infected (IF) animals was measured using densitometry and plotted. ** ${ }^{*}<0.01$ (b) Western blot of lysates obtained from uninfected (UI, lane 1) and LP-BM5 infected (Inf, lanes 2 to 5) animals' DRG (L3-L5) probed with anti-3-nitrotyrosine antibodies. Each lane displays a tissue extract pooled from three individual animals at 10 weeks p.i. The band labeled a represents a high MW protein, and the $\mathbf{b}$ band represents the lower MW protein band that are nitrosylated. The signal intensity of both $\mathbf{a}$ and $\mathbf{b}$ protein bands for uninfected $(\mathrm{UI})$ and infected $(\mathrm{IF})$ animals was measured and is plotted alongside. ${ }^{* *} p<0.01 \mathrm{M}=$ protein molecular weight marker ranging from size 15 to $250 \mathrm{kD}$. c IHC staining of LSC and DRG sections (L3-L5) from uninfected and infected (LP-BM5) mice with anti-3-nitrotyrosine antibody (brown) and mouse lgG isotype antibody. Scale bar $=100 \mu \mathrm{m}$ for LSC and $50 \mu \mathrm{m}$ for DRG

KO and WT animals (Fig. 9b). We observed two major protein bands (labeled a and $\mathrm{b}$ ) that were nitrosylated in both LP-BM5-infected WT, as well as PD-1 KO animals. Next, we went on to analyze the expression of iNOS in LSC and DRG tissues post-LP-BM5 infection. We observed elevated mRNA levels of iNOS, both in LSC (Fig. 9c) and DRG (Fig. 9d) tissues of LP-BM5-infected PD-1 KO mice, when compared to infected WT animals.

\section{Discussion}

With the advent of effective combination antiretroviral therapy, HIV infection is no more a symbol of imminent death, but rather a chronic disease that is associated with wide-ranging complications; including painful, HIV-associated neural damage. HIV-associated DSP is often underdiagnosed, which can partially be attributed to lack of understanding of its pathophysiology. With an estimated 37 million people living with HIV and 1.8 million new infections in 2016 [45], and with more people gaining access to antiretroviral therapy, the burden of HIV-DSP pain is a problem of enormous global significance. A study by US Department of Veterans Affairs in 2011 showed the prevalence of HIVsensory neuropathy was $42 \%$ among patients at an outpatient clinic in Australia; 92\% of patients with sensory neuropathy were on antiretroviral treatment [46]. No routinely available therapy has been shown to be effective for treating HIV-DSP pain. Clearly, there is an urgent need to better understand the pathogenesis of infection-induced HIV-DSP, to develop strategies to prevent this debilitating condition, and to find effective treatments to control its symptoms.

Prior to the induction of cART, DSP in HIV-infected patients was clearly correlated with high plasma viral loads. Hence, in this study, we examined LP-BM5 retroviral load in the LSC and DRG of our infected 


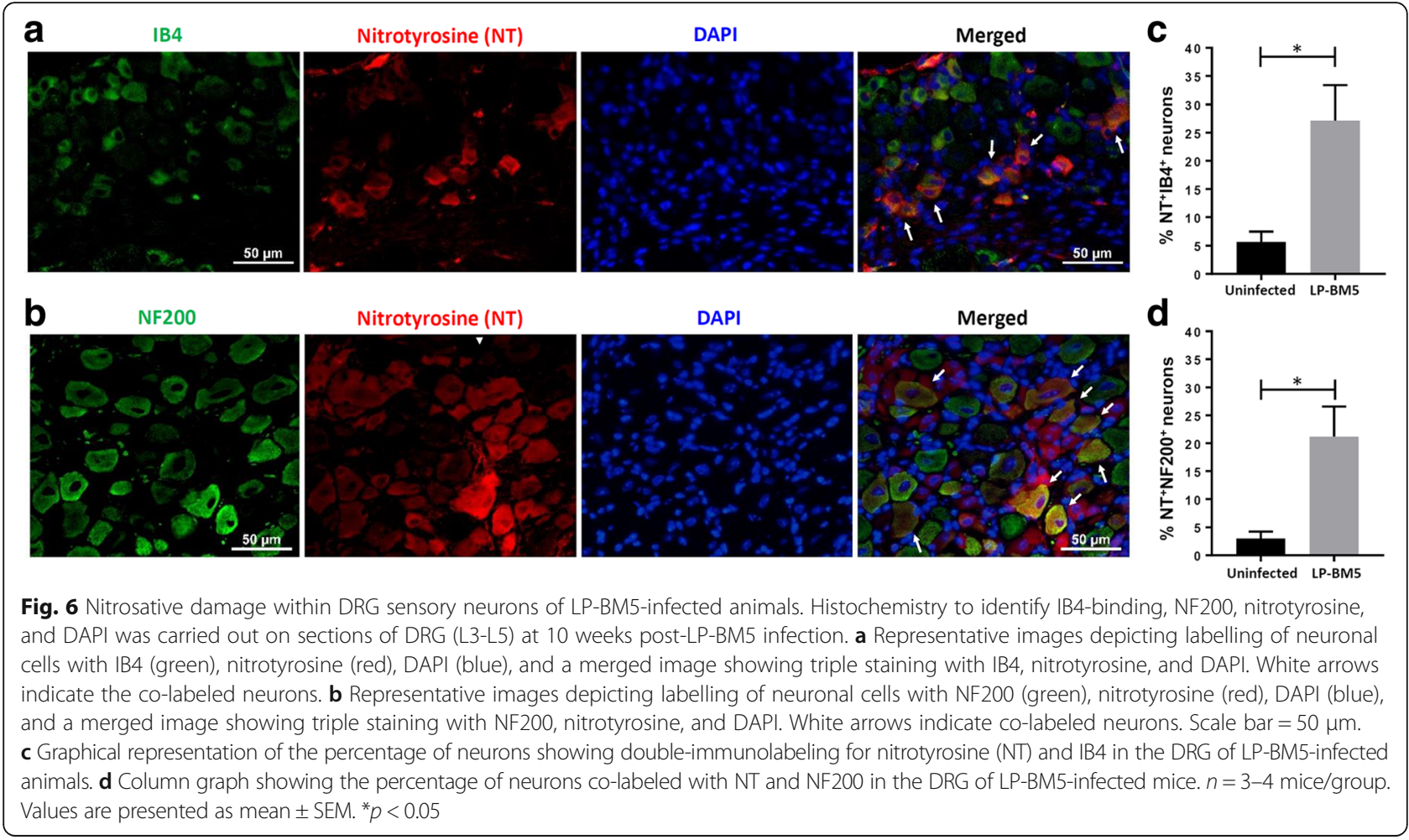

animals. Viral loads were found to persist within both tissues. However, since the disease has persisted even with early use of cART and well-controlled viral infection, this association has recently become less clear. Paradoxically, patients with HIV-associated neuropathic pain often present enhanced, chronic peripheral immune activation, simultaneous with systemic immunodeficiency. A clear association exists between the diagnosis of low $\mathrm{CD}_{4}^{+} \mathrm{T}$ cell count and the development of HIV-associated DSP $[47,48]$. In this study, we reported the long-term production of IFN- $\gamma$ in both LSC and DRG of MAIDS animals, thereby establishing a state of chronic immune activation. Despite these findings, whether development of peripheral neuropathy depends directly on immune activation or viral-induced immunodeficiency has not been investigated in detail. So, the mechanism by which HIV-associated sensory neuropathies develop continues to be the subject of debate. In this study, we investigated the association of immune dysregulation during chronic viral infection with neuropathic pain. Results reported here demonstrate that development of mechanical hind-paw hypersensitivity was closely associated with neuroimmune dysregulation. Recently, it has become apparent that normal immune downregulating mechanisms, such as the PD-1 pathway, limit the magnitude or duration of antiviral T-cell responses. Therefore, strategies to inhibit such negative regulation, and thereby improve protective $\mathrm{T}$-cell immunity, are attractive. However, overzealous immune responses generated by blocking these negative checkpoints may also be responsible for neuroimmune pathology, including but not limited to increased hypersensitivity as demonstrated in this study.

Data presented here show that WT as well PD-1 KO mice infected with LP-BM5 displayed behavioral signs (i.e., mechanical allodynia) of peripheral neuropathy post-infection. We focused on hind-paw hypersensitivity because development of HIV-associated peripheral neuropathy often starts in the lower limbs. Patients with HIV-sensory neuropathies typically present classical distal bilateral sensory symptoms of an axonal, lengthdependent polyneuropathy, in a "stocking and glove" distribution with the feet being first affected. Most often, distal regions of the nerve fibers are first affected, with changes eventually progressing proximally [18]. We cannot negate behavioral or pathological changes in the fore paws, but they were not investigated.

Further experiments went on to determine if the increased mechanical hypersensitivity observed in MAIDS animals was associated with increased cellular infiltration and microglial activation. We have previously found that exacerbated neuroinflammation following immune reconstitution was associated with lethality in LP-BM5-infected animals [26]. Neuroinflammation has been implicated in several non-infectious, neuropathic pain models including traumatic nerve injury and diabetic neuropathy [49]. While, T-cell effector responses play a crucial role in protecting against viral infections [50], they are also involved in pain pathology [51]. It has previously been 

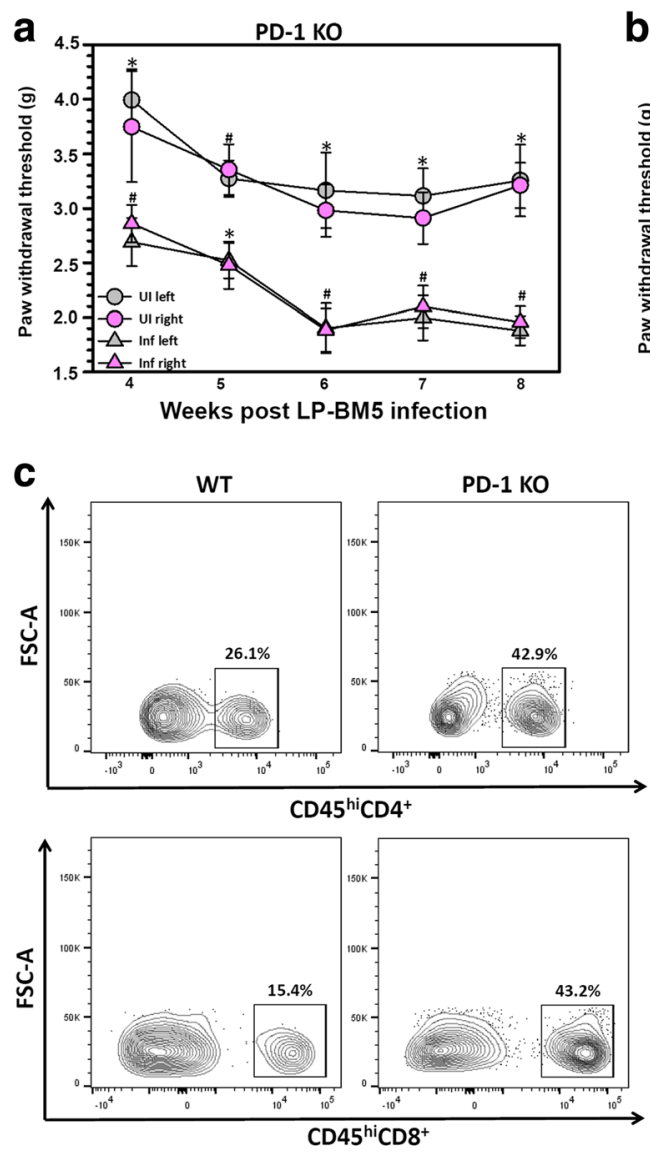
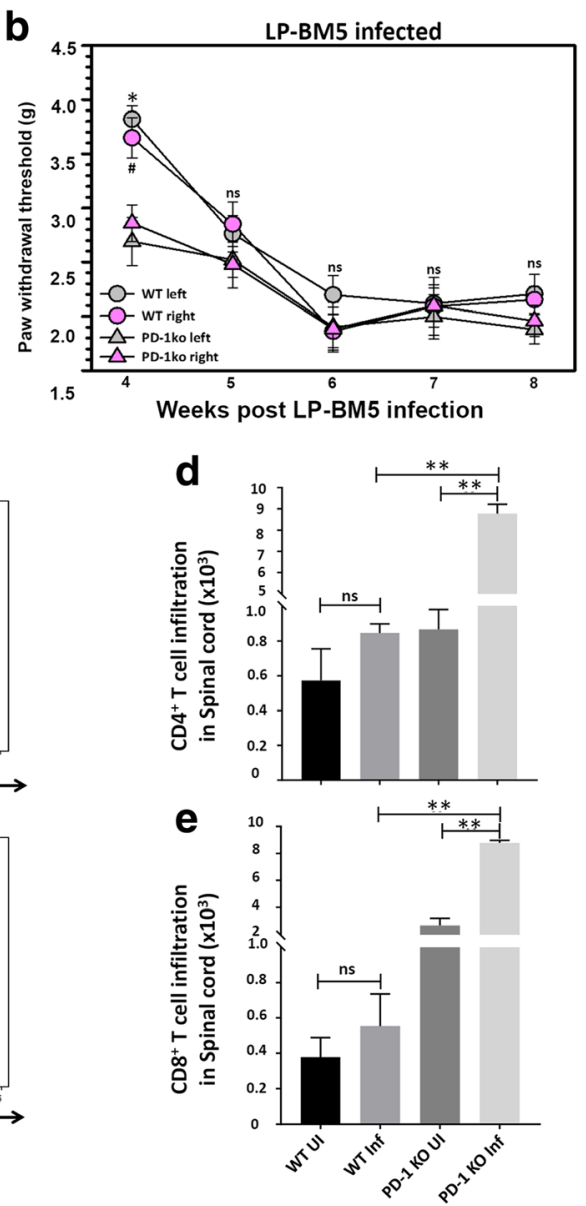

Fig. 7 Accelerated onset of hind-paw mechanical hypersensitivity in PD-1 KO animals infected with LP-BM5 and associated cellular infiltration. Hind-paw withdrawal threshold was assessed in both WT, as well as PD-1 KO, animals as described in Fig. 1. a Paw withdrawal threshold (in grams) was assessed at various time points in LP-BM5-infected (Inf) PD-1 KO animals, as well their age-matched uninfected (UI) littermates $\left(n=10 /\right.$ group). ${ }^{*} p<0.05$ between infected (Inf) and uninfected (UI) PD-1 KO animals, and \#p<0.05 between PD-1KO-infected (Inf) and uninfected (UI) PD-1 KO animals (left and right paws, respectively). b Paw withdrawal threshold was assessed at various time points in LP-BM5-infected WT, as well as PD-1 KO animals ( $n=10 /$ group). ${ }^{*} p<0.05$ between infected PD-1 KO and infected WT animals, and \#p $<0.05$ between infected PD-1 KO and infected WT animals (left and right paws, respectively). Data are presented as mean \pm SEM paw withdrawal threshold. c Representative contour plots show the percentages of $C D 4^{+}$and $C D 8^{+} T$ lymphocytes within infected spinal cords of WT, as well as PD-1 KO animals at 4 weeks p.i. d CD4 ${ }^{+}$T-cell infiltration into the spinal cord of uninfected and infected WT and PD-1 KO animals. e CD8 ${ }^{+}$T-cell infiltration into the spinal cord of uninfected and infected WT and PD-1 KO animals. Pooled data present absolute numbers (mean $\pm \mathrm{SD}$ ) of $\mathrm{CD}^{+}$and $\mathrm{CD} 8^{+} \mathrm{T}$-cells from two independent experiments using three animals per group. ${ }^{* *} p<0.01$

shown that T-cells are essential for the amelioration of paclitaxel-induced neuropathic pain [52]. In addition, animals without $\mathrm{T}$ lymphocytes (i.e., nude mice and rats) are known to exhibit significantly reduced mechanical hypersensitivity in nerve injury models. It is also wellestablished that $\mathrm{CD} 4^{+} \mathrm{T}$-cells infiltrate the spinal cord and contribute to development of neuropathic pain [53]. In accordance with the cited literature, we showed increased infiltration of T-lymphocytes in the spinal cord and DRG of LP-BM5-infected animals experiencing mechanical hypersensitivity. Similar experiments were carried out that demonstrated the increased mechanical hypersensitivity observed in PD-1 KO animals at 4 weeks post-LP-BM5 infection was associated with increased immune cell infiltration.
Numerous studies have demonstrated the role of activated microglia in development of HIV-associated neurological disorders [54-59]. Correspondingly, studies have also shown that spinal cord glial activation, and their subsequent production of proinflammatory cytokines, can contribute to development of sensory hypersensitivity (a behavioral sign of peripheral neuropathy) [60, 61]. Glial cells have been reported to produce pro-inflammatory molecules capable of contributing to LP-BM5-induced neuronal damage [20,62]. Moreover, it has been reported that glial cells play a major role in the modulations of pain mechanisms in the spinal cord where there is communication between neurons and microglia. During nerve injury, $\mathrm{P}_{2} \mathrm{X}_{4}$ receptors on microglia are activated by ATP and 


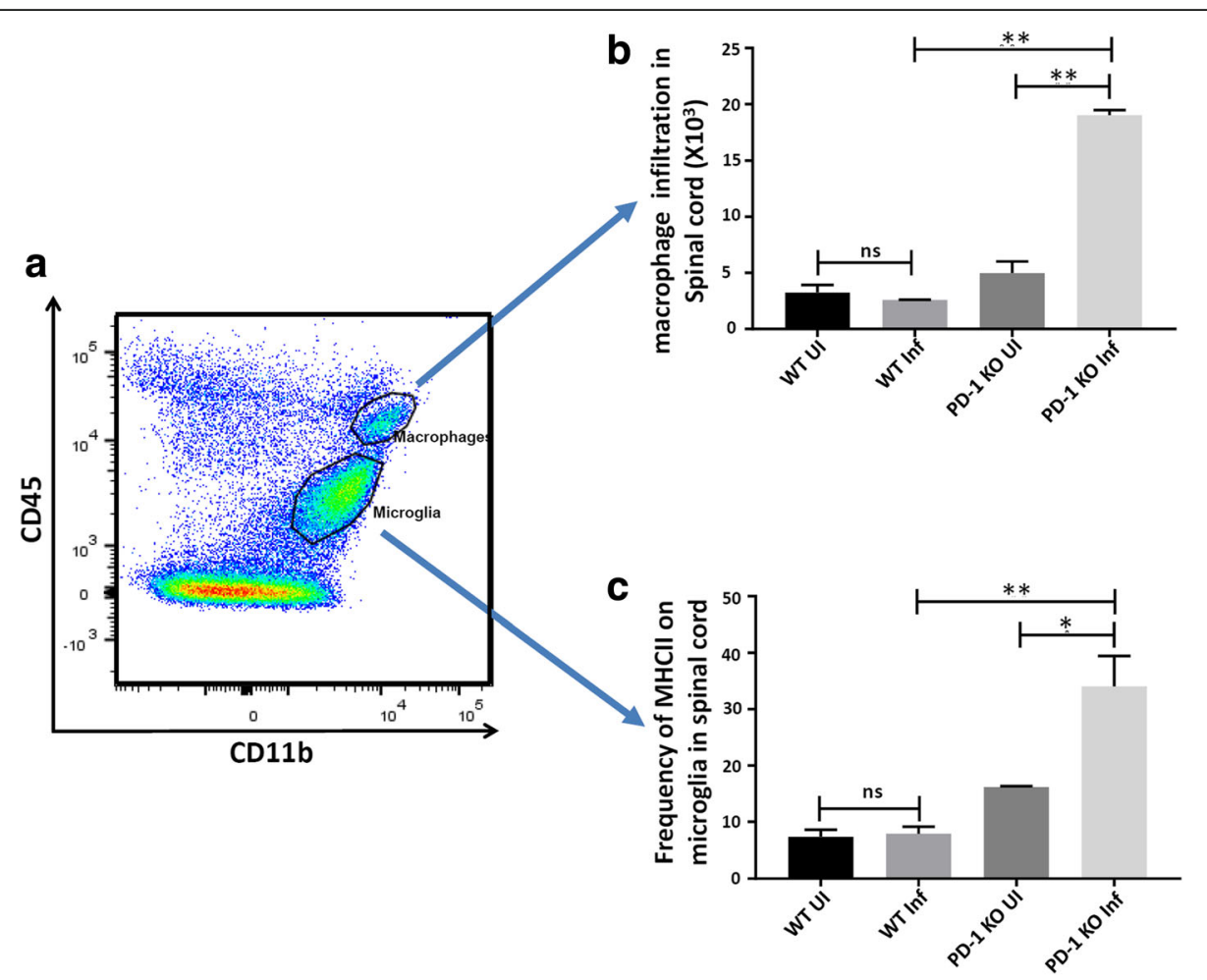

Fig. 8 Increased macrophage infiltration and chronic microglial activation in the spinal cord of LP-BM5-infected PD-1 KO animals. a Representative dot plot to distinguish infiltrating macrophages from tissue-resident microglia. b Absolute numbers of macrophages in the spinal cord of uninfected (UI) and infected (Inf) WT and PD-1 KO animals. Pooled data present absolute numbers (mean \pm SD) of infiltrating macrophages within infected and uninfected WT and PD-1 KO animals at 4 weeks p.i. from two independent experiments using three animals per group. ${ }^{*} p<0.01$. c Pooled data present the frequency (mean \pm SD) of microglial cells expressing MHCll in spinal cord tissues of uninfected (UI) and infected (Inf) WT as well as PD-1 KO animals at 4 weeks p.i. ${ }^{*} p<0.05,{ }^{* *} p<0.01$

release brain-derived neurotrophic factor (BDNF) which, through the activation of neuronal TrkB receptors, alters neuronal excitability. This results in the development of behavioral ipsilateral allodynia [63]. MHC class II expression on microglia is considered a surrogate marker for microglial activation [25]. We went on to analyze microglial cells for activation by detecting MHC class II expression. Our study demonstrated elevated levels of MHCII mRNA ( 3-fold) in the spinal cord of LP-BM5-infected animals by RT-PCR as well as the frequency of microglial cells expressing MHCII was higher ( 20-fold) as measured by flow cytometry. The stability of mRNA is different than that of proteins, MHCII mRNA was also measured in the whole spinal cord while in the flow cytometry experiments, only microglial cells were analyzed for MHCII expression. As expected, the level of microglial activation was found to be higher in PD-1 KO animals.

Increasing attention is being focused on non-neuronal mechanisms involving immune cells that may amplify or resolve chronic pain [64]. Cells and cytokines conventionally believed to act as coordinators of inflammatory responses are becoming well-accepted as modulators of pain signaling $[65,66]$. Viral infections induce neuroinflammation through activation of immune cells, such as macrophages and microglia followed by secretion of neuro-modulatory substances that enhance neuronal excitability and generate pain hypersensitivity [60]. While HIV itself does not replicate in neurons, neuropathological studies have demonstrated the presence of proviral DNA, mRNA, and p24 antigen within macrophages in peripheral nerves [67-69], and in DRG of HIV-infected patients [70, 71]. In addition to T-cells, macrophage infiltration into the peripheral nerves and DRG has been reported in HIV-DSP, as well as other sensory neuropathies $[72,73]$. Therefore, we investigated macrophage infiltration into the spinal cord of our LPBM5-infected mice [65]. The results obtained clearly show significant increase in the macrophage infiltration in LPBM5-infected PD-1 KO animals exhibiting symptoms of DSP at 4 weeks p.i.

Oxidative damage to the CNS is a well-established consequence of viral brain infection. It has been previously shown that activated microglia are the major source of inducible NO synthase (iNOS) and mediate neuronal injury [74, 75]. In this study, we measured expression of iNOS mRNA in the LSC and DRG tissues 


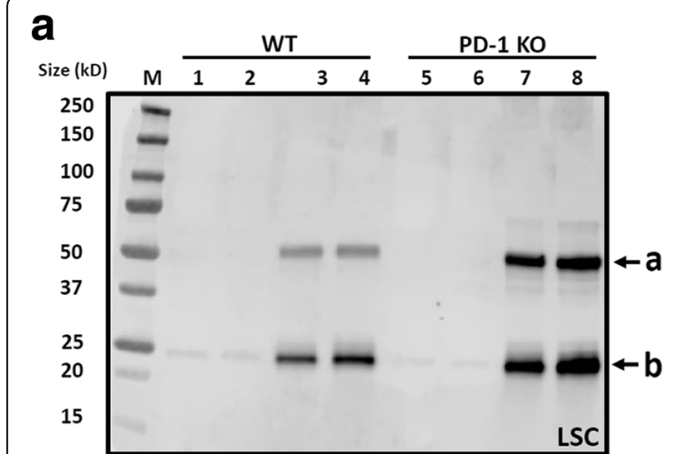

b

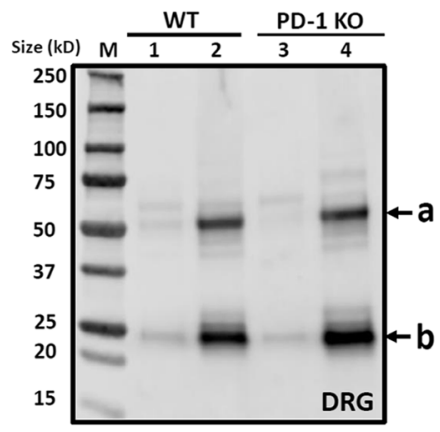

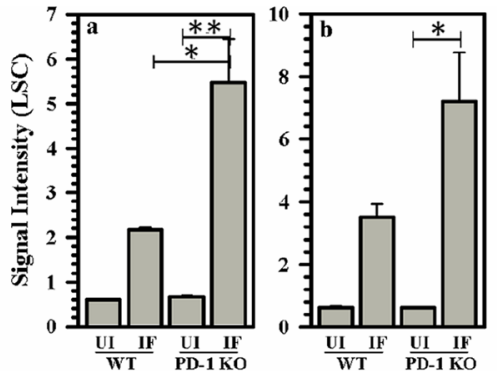

C

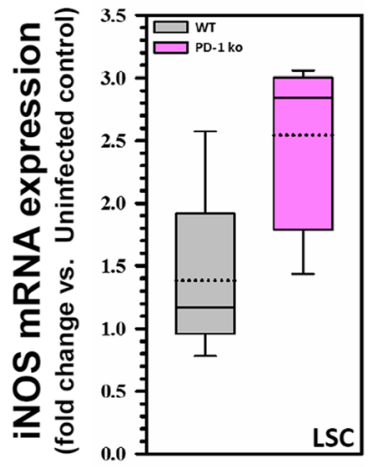

d

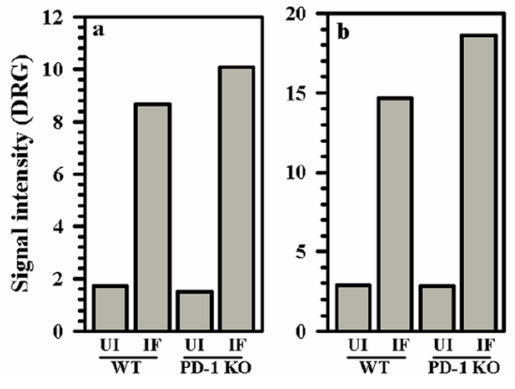

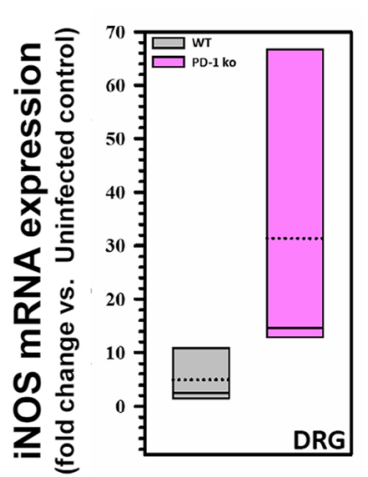

Fig. 9 NO-induced damage within the LSC and DRG of LP-BM5 infected PD-1 KO animals. a Western blot of LSC tissue lysates from uninfected (UI) and LP-BM5-infected (Inf) WT (UI, lanes 1 and 2; Inf, lanes 3 and 4) and PD-1 KO (UI, lanes 5 and 6; Inf, lanes 7 and 8) animals probed with anti-3-nitrotyrosine antibodies. Each lane displays tissue extract from one individual animal at 10 weeks p.i. The band labeled $\mathbf{a}$ identifies a high molecular weight (MW) protein band, while the $\mathbf{b}$ band points out a lower MW protein, both of which are nitrosylated. The signal intensity of both $\mathbf{a}$ and $\mathbf{b}$ protein bands observed in the lysates of uninfected and LP-BM5-infected WT and PD-1 KO animals was measured using densitometry and plotted alongside. ${ }^{*} p<0.05,{ }^{* *} p<0.01$ (b) western blot of lysates obtained from uninfected (UI) and LP-BM5-infected (IF) WT (UI, lane 1 and IF, lane 2) and PD-1 KO (UI, lane 3 and IF, lane 4) animals' DRG (L3-L5) probed with anti-3-nitrotyrosine antibodies. Each lane displays tissue extract pooled from 3 animals at 10 weeks p.i. The band labeled $\mathbf{a}$ identifies a high MW protein band, and $\mathbf{b}$ represents the lower MW protein band that are nitrosylated. The signal intensity of both $\mathbf{a}$ and $\mathbf{b}$ protein bands observed was measured and plotted alongside. $\mathrm{M}=$ protein molecular weight marker ranging from size 15 to 250 kD. c iNOS expression was measured by real-time RT-PCR in the LSC (L3-L5) of LP-BM5-infected WT and PD-1 KO animals at 10 weeks p.i. $(n=4-6)$. $\mathbf{d}$ iNOS mRNA expression in DRG tissues at 10 weeks p.i. via real-time RT-PCR $(n=4-6)$. Results are presented as box plots of pooled data from individual animals

of infected animals and as expected we observed higher expression of iNOS mRNA in infected PD-1 KO animals, which supports the neuronal damage to these animals. It has also been shown that brain sections obtained from patients with AIDS dementia show intense immunostaining for nitrotyrosine, indicating that reaction between $\mathrm{NO}$ and superoxide has led to peroxynitirite (ONOO-) formation [76]. Moreover, nitrotyrosine has been demonstrated as a new therapeutic biomarker for peripheral diabetic neuropathy, and there are increasing evidence for the role of nitrosative stress in the development of early neuropathy [77-80]. We next assessed NO-induced damage by investigating the presence of nitrotyrosine in the LSC and DRG of animals infected with LP-BM5 exhibiting neuropathic pain by using anti-nitrotyrosine antibody. This antibody stains all proteins with tyrosine moieties that have been nitrosylated.
The extent of protein nitrotyrosine formation provides an index of the production of reactive nitrogen species and potential cell damage. In our study, we observed the presence of two major proteins that were nitrosylated postLP-BM5 infection. These proteins need to be further characterized to obtain insight on their role in neuronal damage post-LP-BM5 infection. These experiments revealed elevated levels of 3-nitrotyrosine within LSC and DRG of infected animals; indicative of peroxynitrite, as well as other nitrogen-centered oxidant-induced protein damage. To gain insight into infection-induced neuronal damage, we stained DRG sections for binding of IB4 or NF200 [8], along with 3-nitrotyrosine [81]. These double-labelling studies demonstrated that 3-nitrotyrosine was present in both small $\mathrm{IB}_{4}^{+}$ (non-peptidergic, unmyelinated afferent cell bodies) and $\mathrm{NF}^{200}{ }^{+}$(large myelinated afferent cell bodies) neurons. These data indicate that LP-BM5 infection caused damage 
to both small and large neurons in our animal model. Further, infected PD-1 KO animals displayed greater expression of 3-nitrotyrosine as compared to WT animals early during infection, which correlated with their greater hind-paw mechanical hypersensitivity.

Currently, there are no FDA-approved pharmacologic agents available which are specifically designed for treatment of chronic HIV-associated neuropathy. The analgesics currently used target neurons (i.e., opioids), but these drugs are only modestly effective for chronic pain and have significant CNS side effects [82]. Our study supports the approach of using inhibitors of microglial activation to limit immune activation-induced neuropathic damage and, correspondingly, ameliorate peripheral neuropathy [83].

Our findings demonstrated that during retroviral infection, circulating $\mathrm{CD}_{4}^{+}$and $\mathrm{CD} 8^{+}$T-cells, as well as macrophages, cross the blood-nerve barrier and enter the spinal cord to perform surveillance functions. This cellular infiltration, along with reactive gliosis, is associated with increased neuropathic pain resulting in neuronal damage. However, these are certainly not the sole factors and the mechanistic linkage between cellular infiltration and pain remains to be determined. In subsequent studies we will investigate mechanisms driving neuronal damage and the development of neuropathic pain.

\section{Conclusions}

Although, it has previously been reported that LP-BM5 infection results in enhanced mechanical hypersensitivity to pain [18], in this study, we demonstrated the linkage between neuropathic pain and nitrosative damage to the neurons in LSC and DRG. Furthermore, knocking out the PD-1: PD-L1 negative checkpoint pathway was found to aggravate pain sensitivity. The observed mechanical hypersensitivity in LP-BM5-infected animals was found to be associated with increased infiltration of $\mathrm{CD}_{4}^{+}$and $\mathrm{CD}^{+}$ T-cells, increased macrophage infiltration, and reactive gliosis in the spinal cord. These findings will help further elucidate mechanisms underlying HIV DSP and may be used to test candidate therapeutics.

\section{Abbreviations \\ CART: Combination antiretroviral therapy; CGRP: Calcitonin gene-related pep- tide; DRG: Dorsal root ganglion; DSP: Distal symmetrical polyneuropathy; HIV: Human Immunodeficiency virus; i.p.: Intraperitonial; Iba: Ionized calcium binding adaptor molecule; IENF: Intraepidermal nerve fiber: \\ IHC: Immunohistochemistry; LSC: Lumbar spinal cord; MAIDS: Murine- acquired immunodeficiency syndrome; p.i.: Post infection; PD: Programmed death; PGP 9.5: Protein Gene Product 9.5; WT: Wild-type}

\section{Acknowledgements}

Not applicable.

\section{Funding}

This work was supported by award DA-039464 from the National Institute on Drug Abuse. The funders had no role in study design, data collection and analysis, decision to publish, or preparation of the manuscript.
Availability of data and materials

Data supporting the conclusions of this article are presented in the manuscript.

\section{Authors' contributions}

PC, WS, SH, and JL conceived and designed the experiments. PC, SH, WS, and SP performed the experiments. PC and JL wrote the main manuscript text. All authors read and approved the manuscript.

\section{Ethics approval}

This study was carried out in strict accordance with recommendations in the Guide for the Care and Use of Laboratory Animals of the National Institutes of Health. The protocol was approved by the Institutional Animal Care and Use Committee (protocol number: 1709-35110A and breeding protocol number: 1702-34587A) of the University of Minnesota.

\section{Consent for publication}

Not applicable.

\section{Competing interests}

The authors declare that they have no competing interests.

\section{Publisher's Note}

Springer Nature remains neutral with regard to jurisdictional claims in published maps and institutional affiliations.

Received: 21 September 2017 Accepted: 26 February 2018

Published online: 05 March 2018

\section{References}

1. Morgello S, Estanislao L, Simpson D, Geraci A, DiRocco A, Gerits P, Ryan E, Yakoushina T, Khan S, Mahboob R, et al. HIV-associated distal sensory polyneuropathy in the era of highly active antiretroviral therapy: the Manhattan HIV brain Bank. Arch Neurol. 2004;61:546-51.

2. Ellis RJ, Rosario D, Clifford DB, McArthur JC, Simpson D, Alexander T, Gelman $B B$, Vaida F, Collier A, Marra CM, et al. Continued high prevalence and adverse clinical impact of human immunodeficiency virus-associated sensory neuropathy in the era of combination antiretroviral therapy: the CHARTER study. Arch Neurol. 2010;67:552-8.

3. Evans SR, Ellis RJ, Chen H, Yeh TM, Lee AJ, Schifitto G, Wu K, Bosch RJ, JC MA, Simpson DM, Clifford DB. Peripheral neuropathy in HIV: prevalence and risk factors. AIDS. 2011;25:919-28.

4. Phillips TJ, Cherry CL, Cox S, Marshall SJ, Rice AS. Pharmacological treatment of painful HIV-associated sensory neuropathy: a systematic review and meta-analysis of randomised controlled trials. PLoS One. 2010;5:e14433.

5. Gonzalez-Duarte A, Robinson-Papp J, Simpson DM. Diagnosis and management of HIV-associated neuropathy. Neurol Clin. 2008;26:821-32. x

6. Cornblath DR, Hoke A. Recent advances in HIV neuropathy. Curr Opin Neurol. 2006;19:446-50.

7. Chen H, Clifford DB, Deng L, Wu K, Lee AJ, Bosch RJ, Riddler SA, Ellis RJ, Evans SR. Peripheral neuropathy in ART-experienced patients: prevalence and risk factors. J Neuro-Oncol. 2013;19:557-64.

8. Makker PG, Duffy SS, Lees JG, Perera CJ, Tonkin RS, Butovsky O, Park SB, Goldstein D, Moalem-Taylor G. Characterisation of immune and neuroinflammatory changes associated with chemotherapy-induced peripheral neuropathy. PLoS One. 2017;12:e0170814.

9. Hulgan T, Haas DW, Haines JL, Ritchie MD, Robbins GK, Shafer RW, Clifford DB, Kallianpur AR, Summar M, Canter JA. Mitochondrial haplogroups and peripheral neuropathy during antiretroviral therapy: an adult AIDS clinical trials group study. AIDS. 2005;19:1341-9.

10. Kallianpur AR, Hulgan T. Pharmacogenetics of nucleoside reversetranscriptase inhibitor-associated peripheral neuropathy. Pharmacogenomics. 2009;10:623-37.

11. Kamerman PR, Moss PJ, Weber J, Wallace VC, Rice AS, Huang W. Pathogenesis of HIV-associated sensory neuropathy: evidence from in vivo and in vitro experimental models. J Peripher Nerv Syst. 2012;17:19-31.

12. Jones G, Zhu Y, Silva C, Tsutsui S, Pardo CA, Keppler OT, McArthur JC, Power C. Peripheral nerve-derived HIV-1 is predominantly CCR5-dependent and causes neuronal degeneration and neuroinflammation. Virology. 2005;334:178-93. 
13. Wallace VC, Blackbeard J, Segerdahl AR, Hasnie F, Pheby T, McMahon SB, Rice AS. Characterization of rodent models of HIV-gp120 and anti-retroviralassociated neuropathic pain. Brain. 2007;130:2688-702.

14. Keswani SC, Jack C, Zhou C, Hoke A. Establishment of a rodent model of HIV-associated sensory neuropathy. J Neurosci. 2006;26:10299-304.

15. Zink MC, Laast VA, Helke KL, Brice AK, Barber SA, Clements JE, Mankowski JL. From mice to macaques-animal models of HIV nervous system disease. Curr HIV Res. 2006;4:293-305.

16. Laast VA, Shim B, Johanek LM, Dorsey JL, Hauer PE, Tarwater PM, Adams RJ, Pardo CA, McArthur JC, Ringkamp M, Mankowski JL. Macrophage-mediated dorsal root ganglion damage precedes altered nerve conduction in SIVinfected macaques. Am J Pathol. 2011;179:2337-45.

17. Burdo TH, Orzechowski K, Knight HL, Miller AD, Williams K. Dorsal root ganglia damage in SIV-infected rhesus macaques: an animal model of HIVinduced sensory neuropathy. Am J Pathol. 2012:180:1362-9.

18. Cao L, Butler MB, Tan L, Draleau KS, Koh WY. Murine immunodeficiency virus-induced peripheral neuropathy and the associated cytokine responses. J Immunol. 2012;189:3724-33.

19. Cao L, Butler MB. Involvement of microglial CD40 in murine retrovirusinduced peripheral neuropathy. J Neuroimmunol. 2013;261:37-43.

20. Kustova Y, Grinberg A, Basile AS. Increased blood-brain barrier permeability in LP-BM5 infected mice is mediated by neuroexcitatory mechanisms. Brain Res. 1999;839:153-63.

21. Sei Y, Kustova Y, Li Y, Morse HC 3rd, Skolnick P, Basile AS. The encephalopathy associated with murine acquired immunodeficiency syndrome. Ann N Y Acad Sci. 1998;840:822-34.

22. Chattopadhyay SK, Sengupta DN, Fredrickson TN, Morse HC 3rd, Hartley JW. Characteristics and contributions of defective, ecotropic, and mink cell focus-inducing viruses involved in a retrovirus-induced immunodeficiency syndrome of mice. J Virol. 1991;65:4232-41.

23. Mosier DE, Yetter RA, Morse HC 3rd. Retroviral induction of acute lymphoproliferative disease and profound immunosuppression in adult C57BL/6 mice. J Exp Med. 1985;161:766-84.

24. Jolicoeur P. Murine acquired immunodeficiency syndrome (MAIDS): an animal model to study the AIDS pathogenesis. FASEB J. 1991;5:2398-405.

25. Mutnal MB, Hu S, Little MR, Lokensgard JR. Memory T cells persisting in the brain following MCMV infection induce long-term microglial activation via interferon-gamma. J Neuro-Oncol. 2011;17:424-37.

26. Mutnal MB, Schachtele SJ, Hu S, Lokensgard JR. T-cell reconstitution during murine acquired immunodeficiency syndrome (MAIDS) produces neuroinflammation and mortality in animals harboring opportunistic viral brain infection. J Neuroinflammation. 2013;10:98.

27. Hu S, Sheng WS, Schachtele SJ, Lokensgard JR. Reactive oxygen species drive herpes simplex virus (HSV)-1-induced proinflammatory cytokine production by murine microglia. J Neuroinflammation. 2011;8:123.

28. Marques CP, Cheeran MC, Palmquist JM, Hu S, Urban SL, Lokensgard $J R$. Prolonged microglial cell activation and lymphocyte infiltration following experimental herpes encephalitis. J Immunol. 2008;181: 6417-26.

29. Ji RR, Berta T, Nedergaard M. Glia and pain: is chronic pain a gliopathy? Pain. 2013;154(Suppl 1):S10-28.

30. DeLeo JA, Yezierski RP. The role of neuroinflammation and neuroimmune activation in persistent pain. Pain. 2001;90:1-6.

31. Marchand F, Perretti M, McMahon SB. Role of the immune system in chronic pain. Nat Rev Neurosci. 2005;6:521-32.

32. Lehmann HC, Kohne A, Meyer zu Horste G, Dehmel T, Kiehl O, Hartung HP, Kastenbauer S, Kieseier BC. Role of nitric oxide as mediator of nerve injury in inflammatory neuropathies. J Neuropathol Exp Neurol. 2007;66:305-12.

33. Freeman GJ, Wherry EJ, Ahmed R, Sharpe AH. Reinvigorating exhausted HIVspecific T cells via PD-1-PD-1 ligand blockade. J Exp Med. 2006;203:2223-7.

34. Day CL, Kaufmann DE, Kiepiela P, Brown JA, Moodley ES, Reddy S, Mackey EW, Miller JD, Leslie AJ, DePierres C, et al. PD-1 expression on HIV-specific T cells is associated with T-cell exhaustion and disease progression. Nature. 2006:443:350-4

35. Green KA, Okazaki T, Honjo T, Cook WJ, Green WR. The programmed death1 and interleukin-10 pathways play a down-modulatory role in LP-BM5 retrovirus-induced murine immunodeficiency syndrome. J Virol. 2008;82: 2456-69.

36. Li W, Green WR. Immunotherapy of murine retrovirus-induced acquired immunodeficiency by CD4 T regulatory cell depletion and PD-1 blockade. J Virol. 2011;85:13342-53.
37. Elrefaei M, Baker CA, Jones NG, Bangsberg DR, Cao H. Presence of suppressor HIV-specific CD8+ T cells is associated with increased PD-1 expression on effector CD8+ T cells. J Immunol. 2008;180:7757-63.

38. Cheeran MC, Hu S, Palmquist JM, Bakken T, Gekker G, Lokensgard JR. Dysregulated interferon-gamma responses during lethal cytomegalovirus brain infection of IL-10-deficient mice. Virus Res. 2007;130:96-102.

39. Ford AL, Goodsall AL, Hickey WF, Sedgwick JD. Normal adult ramified microglia separated from other central nervous system macrophages by flow cytometric sorting. Phenotypic differences defined and direct ex vivo antigen presentation to myelin basic protein-reactive CD4+ T cells compared. J Immunol. 1995;154:4309-21.

40. Marten NW, Stohlman SA, Zhou J, Bergmann CC. Kinetics of virus-specific CD8+ -T-cell expansion and trafficking following central nervous system infection. J Virol. 2003;77:2775-8.

41. Liu L, Yin Y, Li F, Malhotra C, Cheng J. Flow cytometry analysis of inflammatory cells isolated from the sciatic nerve and DRG after chronic constriction injury in mice. J Neurosci Methods. 2017:284:47-56.

42. Livak KJ, Schmittgen TD. Analysis of relative gene expression data using real-time quantitative PCR and the 2(-Delta Delta C(T)) method. Methods. 2001;25:402-8

43. Schachtele SJ, Hu S, Sheng WS, Mutnal MB, Lokensgard JR. Glial cells suppress postencephalitic CD8+ T lymphocytes through PD-L1. Glia. 2014; 62:1582-94

44. Chauhan P, Hu S, Sheng WS, Prasad S, Lokensgard JR. Modulation of microglial cell Fcgamma receptor expression following viral brain infection. Sci Rep. 2017;7:41889.

45. UNAIDS/AIDSinfo. http://www.unaids.org/en/resources/fact-sheet/. Accessed 29 Jan 2018.

46. U.S. Department of Veterans Affairs/ HIV/AIDS. https:/wwww.hiv.va.gov/provider/ manual-primary-care/peripheral-neuropathy.asp. Accessed 29 Jan 2018.

47. So YT, Holtzman DM, Abrams DI, Olney RK. Peripheral neuropathy associated with acquired immunodeficiency syndrome. Prevalence and clinical features from a population-based survey. Arch Neurol. 1988;45:945-8.

48. Schifitto G, McDermott MP, McArthur JC, Marder K, Sacktor N, Epstein L, Kieburtz K, Dana Consortium on the Therapy of HIVD, Related Cognitive D. Incidence of and risk factors for HIV-associated distal sensory polyneuropathy. Neurology. 2002;58:1764-8.

49. Ellis A, Bennett DL. Neuroinflammation and the generation of neuropathic pain. Br J Anaesth. 2013;111:26-37.

50. Yetter RA, Buller RM, Lee JS, Elkins KL, Mosier DE, Fredrickson TN, Morse HC 3rd. CD4+ T cells are required for development of a murine retrovirus-induced immunodeficiency syndrome (MAIDS). J Exp Med. 1988;168:623-35.

51. Ji RR, Chamessian A, Zhang YQ. Pain regulation by non-neuronal cells and inflammation. Science. 2016;354:572-7.

52. Krukowski K, Eijkelkamp N, Laumet G, Hack CE, Li Y, Dougherty PM, Heijnen CJ, Kavelaars A. CD8+ T cells and endogenous IL-10 are required for resolution of chemotherapy-induced neuropathic pain. J Neurosci. 2016;36:1 1074-83.

53. Grace PM, Rolan PE, Hutchinson MR. Peripheral immune contributions to the maintenance of central glial activation underlying neuropathic pain. Brain Behav Immun. 2011;25:1322-32.

54. Kraft-Terry SD, Buch SJ, Fox HS, Gendelman HE. A coat of many colors: neuroimmune crosstalk in human immunodeficiency virus infection. Neuron. 2009:64:133-45.

55. Ji RR, Suter MR. p38 MAPK, microglial signaling, and neuropathic pain. Mol Pain. 2007;3:33.

56. Raghavendra V, Tanga F, DeLeo JA. Inhibition of microglial activation attenuates the development but not existing hypersensitivity in a rat model of neuropathy. J Pharmacol Exp Ther. 2003;306:624-30.

57. Tsuda M, Shigemoto-Mogami Y, Koizumi S, Mizokoshi A, Kohsaka S, Salter MW, Inoue K. P2X4 receptors induced in spinal microglia gate tactile allodynia after nerve injury. Nature. 2003;424:778-83.

58. Coull JA, Beggs S, Boudreau D, Boivin D, Tsuda M, Inoue K, Gravel C, Salter MW, De Koninck Y. BDNF from microglia causes the shift in neuronal anion gradient underlying neuropathic pain. Nature. 2005;438:1017-21.

59. Ren K, Dubner R. Interactions between the immune and nervous systems in pain. Nat Med. 2010;16:1267-76.

60. Milligan ED, Watkins LR. Pathological and protective roles of glia in chronic pain. Nat Rev Neurosci. 2009;10:23-36.

61. Herzberg U, Sagen J. Peripheral nerve exposure to HIV viral envelope protein gp120 induces neuropathic pain and spinal gliosis. J Neuroimmunol. 2001;116:29-39. 
62. Suzumura A, Sawada M, Takayanagi T. Production of interleukin-12 and expression of its receptors by murine microglia. Brain Res. 1998;787:139-42.

63. Malcangio M. Spinal mechanisms of neuropathic pain: is there a P2X4-BDNF controversy? Neurobiol Pain. 2017;1:1-5.

64. Bravo-Caparros I, Nieto FR. Roles for CD8+ T cells and IL-10 in the resolution of paclitaxel-induced neuropathic pain. J Neurosci. 2017;37:2803-5.

65. Abbadie C. Chemokines, chemokine receptors and pain. Trends Immunol. 2005;26:529-34.

66. McMahon SB, Cafferty WB, Marchand F. Immune and glial cell factors as pain mediators and modulators. Exp Neurol. 2005;192:444-62.

67. Brannagan TH 3rd, Nuovo GJ, Hays AP, Latov N. Human immunodeficiency virus infection of dorsal root ganglion neurons detected by polymerase chain reaction in situ hybridization. Ann Neurol. 1997;42:368-72.

68. Nagano I, Shapshak P, Yoshioka M, Xin KQ, Nakamura S, Bradley WG. Parvalbumin and calbindin D-28 k immunoreactivity in dorsal root ganglia in acquired immunodeficiency syndrome. Neuropathol Appl Neurobiol. 1996;22:293-301.

69. Rizzuto N, Cavallaro T, Monaco S, Morbin M, Bonetti B, Ferrari S, GaliazzoRizzuto S, Zanette G, Bertolasi L. Role of HIV in the pathogenesis of distal symmetrical peripheral neuropathy. Acta Neuropathol. 1995;90:244-50.

70. Esiri MM, Morris CS, Millard PR. Sensory and sympathetic ganglia in HIV-1 infection: immunocytochemical demonstration of HIV-1 viral antigens, increased MHC class II antigen expression and mild reactive inflammation. J Neurol Sci. 1993;114:178-87.

71. Yoshioka M, Shapshak P, Srivastava AK, Stewart RV, Nelson SJ, Bradley WG, Berger JR, Rhodes RH, Sun NC, Nakamura S. Expression of HIV-1 and interleukin-6 in lumbosacral dorsal root ganglia of patients with AIDS. Neurology. 1994;44:1120-30.

72. Kieseier BC, Hartung HP, Wiendl H. Immune circuitry in the peripheral nervous system. Curr Opin Neurol. 2006;19:437-45.

73. Hahn K, Robinson B, Anderson C, Li W, Pardo CA, Morgello S, Simpson D, Nath A. Differential effects of HIV infected macrophages on dorsal root ganglia neurons and axons. Exp Neurol. 2008;210:30-40.

74. Chao CC, Hu S, Molitor TW, Shaskan EG, Peterson PK. Activated microglia mediate neuronal cell injury via a nitric oxide mechanism. J Immunol. 1992; 149:2736-41.

75. Marques CP, Cheeran MC, Palmquist JM, Hu S, Lokensgard JR. Microglia are the major cellular source of inducible nitric oxide synthase during experimental herpes encephalitis. J Neuro-Oncol. 2008;14:229-38.

76. Boven LA, Gomes L, Hery C, Gray F, Verhoef J, Portegies P, Tardieu M, Nottet HS. Increased peroxynitrite activity in AIDS dementia complex: implications for the neuropathogenesis of HIV-1 infection. J Immunol. 1999;162:4319-27.

77. Drel VR, Lupachyk S, Shevalye H, Vareniuk I, Xu W, Zhang J, Delamere NA, Shahidullah M, Slusher B, Obrosova IG. New therapeutic and biomarker discovery for peripheral diabetic neuropathy: PARP inhibitor, nitrotyrosine, and tumor necrosis factor-a. Endocrinology. 2010;151:2547-55.

78. Obrosova IG, Drel VR, Oltman CL, Mashtalir N, Tibrewala J, Groves JT, Yorek MA. Role of nitrosative stress in early neuropathy and vascular dysfunction in streptozotocin-diabetic rats. Am J Physiol Endocrinol Metab. 2007;293: E1645-55.

79. Vareniuk I, Pavlov IA, Obrosova IG. Inducible nitric oxide synthase gene deficiency counteracts multiple manifestations of peripheral neuropathy in a streptozotocin-induced mouse model of diabetes. Diabetologia. 2008;51: 2126-33.

80. Areti A, Komirishetty P, Kumar A. Carvedilol prevents functional deficits in peripheral nerve mitochondria of rats with oxaliplatin-evoked painful peripheral neuropathy. Toxicol Appl Pharmacol. 2017;322:97-103.

81. Vareniuk I, Pavlov IA, Drel VR, Lyzogubov W, Innytska O, Bell SR, Tibrewala J, Groves JT, Obrosova IG. Nitrosative stress and peripheral diabetic neuropathy in leptin-deficient (Ob/Ob) mice. Exp Neurol. 2007;205:425-36.

82. Smith HS. Treatment considerations in painful HIV-related neuropathy. Pain Physician. 2011;14:E505-24.

83. Rock RB, Peterson PK. Microglia as a pharmacological target in infectious and inflammatory diseases of the brain. J Neurolmmune Pharmacol. 2006;1:117-26.

\section{Submit your next manuscript to BioMed Central and we will help you at every step:}

- We accept pre-submission inquiries

- Our selector tool helps you to find the most relevant journal

- We provide round the clock customer support

- Convenient online submission

- Thorough peer review

- Inclusion in PubMed and all major indexing services

- Maximum visibility for your research

Submit your manuscript at www.biomedcentral.com/submit
Biomed Central 